\title{
Una hacienda local pobre: ¿qué explica la recaudación predial en México?
}

\author{
Poor local finances: \\ What explains property tax collection in Mexico?
}

Mónica Unda Gutiérrez*

\section{Resumen}

Este artículo analiza los principales determinantes de la recaudación predial en México de 1990 a 2010. A través de un estudio estadístico, con base en datos a escala municipal, se examinan las principales hipótesis sugeridas por la literatura para entender los niveles de recaudación; es decir, se evalúa la capacidad explicativa de factores económicos, políticos y administrativos. Por un lado, se analiza qué tanto las variables socioeconómicas del municipio, así como el monto de transferencias que reciben, influyen en la recaudación. Y por otro, se sopesa si la capacidad institucional del municipio y el nivel de competencia política influyen en el monto recaudado de predial. Los hallazgos indican que los municipios que enfrentan mayor competencia electoral tienden a no incrementar la recaudación predial; que la capacidad institucional de tesorerías y catastros también influye; que mientras más rico y urbano sea el municipio, más recauda. Por último, se encuentra que las transferencias fiscales intergubernamentales no han desincentivado la recaudación predial.

Palabras clave: finanzas municipales; predial; capacidad institucional; impuestos a la propiedad; municipios de México.

* Marquette University, Departamento de Ciencias Políticas. Dirección: 1250 W Wisconsin Ave, Milwaukee, WI 53233, Estados Unidos. Correo: monica.unda-gutierrez@marquette. edu ORCID: https://orcid.org/0000-0001-6231-1208

Nota de la autora: Agradezco el financiamiento del Lincoln Institute of Land Policy para poder llevar a cabo la investigación en la que se sustenta este artículo, así como los comentarios de Brian Palmer-Rubin, Claudia De Cesare y Carlos Moreno Jaimes. 


\begin{abstract}
This article analyzes the main determinants of property tax collection in Mexico from 1990 to 2010. Through a statistical study, based on data at the municipal level, the main hypotheses suggested by the literature are examined to understand collection levels. In other words, the explanatory capacity of economic, political, and administrative factors is evaluated. On the one hand, the article analyzes the way both the socioeconomic variables of the municipality, and the amount of transfers they receive, influence tax collection. In addition, on the other, it analyzes whether the institutional capacity of the municipality and the level of political competition influence the amount collected from property. The findings indicate that municipalities facing the greatest electoral competition tend not to increase property tax collection; that the institutional capacity of treasuries and land registers is also an influential factor; and that the richer and more urban the municipality, the more it collects. Finally, it is found that intergovernmental fiscal transfers have not discouraged property tax collection.
\end{abstract}

Keywords: municipal finances; predial; institutional capacity; property taxes; Mexican municipalities.

\title{
I. Introducción
}

Los impuestos a la propiedad, como el predial, suelen ser la espina dorsal de las haciendas locales. Sin embargo, éste no es el caso en México pues el predial en la actualidad aporta sólo el $8.8 \%$ del ingreso municipal. Si bien desde inicios de los años ochenta -desde que el predial es potestad municipal- la recaudación de este impuesto ha aumentado, está muy por debajo de su potencial recaudatorio y de lo que recaudan otros países de ingresos similares. En 2014, según las estadísticas de ingreso de la OCDE, ${ }^{1}$ Chile, Brasil y Uruguay recaudaron $0.59,0.48$ y $0.73 \%$ de su PIB en impuestos a la propiedad, mientras que México recaudó el equivalente a $0.2 \%$ del PIB.

El desempeño mediocre del predial mexicano se ha dado a pesar de que en las últimas tres décadas se han implementado numerosas reformas impulsadas por el gobierno federal para incentivar la recaudación de este impuesto. Por lo anterior, y partiendo de la idea de que los gobiernos municipales deben aumentar sus recursos propios para promover el desarrollo local y disminuir su dependencia del gobierno federal, es relevante esclarecer qué determina la recaudación predial de los gobiernos municipales en México.

El objetivo de este trabajo, entonces, es entender mejor qué factores son los que influyen en el nivel de recaudación predial. Partimos de un mar-

\footnotetext{
${ }^{1}$ https://stats.oecd.org/Index.aspx?DataSetCode=REV
} 
co de referencia teórico que establece que los determinantes de la recaudación son de tres tipos: económicos, administrativos y de economía política. En otras palabras, ponemos a prueba las hipótesis sugeridas por la literatura para explicar los niveles de recaudación. Para valorar el poder explicativo de estos tres tipos de factores, se llevó a cabo un análisis estadístico amplio en observaciones, considerando todos los municipios de México y con datos anuales para cada uno de éstos desde 1990 hasta 2010.

El aumento de la recaudación predial conlleva diversos beneficios; el más evidente sería el dotar de mayor capacidad financiera al municipio para cumplir con sus funciones e impulsar el desarrollo local. ${ }^{2} \mathrm{Si}$ bien el desempeño de las funciones básicas de los gobiernos municipales no sólo está determinado por los recursos financieros con los que cuentan, sino también por su capacidad institucional, la mayoría de los municipios del país tienen recursos fiscales limitados.

Este trabajo realiza varias contribuciones. Sus hallazgos coadyuvan a llenar un hueco en la literatura fiscal municipal en México. Los análisis que han tratado el tema del predial municipal en México son muy pocos y ninguno lo aborda de manera longitudinal ni tan comprensiva incluyendo la totalidad de los municipios del país. ${ }^{3}$ Quizá la falta de estudios en este ámbito tenga que ver con el reto que implica la construcción de series históricas, como las que se han construido para este trabajo, sobre datos municipales fiscales, económicos, electorales y de gobierno. Por último, los hallazgos de esta investigación son útiles para informar a quienes toman decisiones sobre el impuesto predial.

Los hallazgos más relevantes de este estudio cuestionan las explicaciones que se han sugerido previamente para entender la baja captación fiscal de los municipios en México y sugieren que las variables político-electorales y de capacidad institucional en los municipios son importantes para explicar el nivel de recaudación predial. Encontramos, a diferencia de otros trabajos, que las transferencias recibidas por los municipios no desincentivan la recaudación predial. Igualmente, los hallazgos permiten indicar que los gobernantes de los municipios, cuando tienen mayor riesgo de perder las elecciones, no suelen tomar decisiones (impopulares) que lleven al aumento del predial. O lo que es lo mismo: a mayor competencia electoral, menor recaudación predial.

\footnotetext{
${ }^{2}$ Para abundar en las virtudes del predial como un impuesto (i) con alto potencial recaudador, (ii) que implica estabilidad en los ingresos debido a su base, (iii) que cuenta con cierto grado de progresividad y (iv) que permite el ejercicio del principio del beneficio (Musgrave, 1967, pp. 63-119), véase también Unda y Moreno, 2015, pp. 47-48.

${ }^{3}$ Ibarra y Sotres (2009; 2013); Ibarra, González y Sotres (2014); Bustamante (2001); Ruelas Ávila (2012) y Cruz Vázquez (2011).
} 
Este artículo se divide en seis secciones. En la siguiente se presenta el marco teórico al cual se ciñe este trabajo y se expone la tesis que ha sido sugerida para explicar la baja recaudación predial en México. El tercer apartado aborda la trayectoria del predial desde inicios de los años ochenta, en términos de los programas federales y reformas legales que han tenido (o pretendido tener) un impacto en el impuesto. La sección cuarta plantea el diseño del estudio estadístico: aborda la lógica de las hipótesis económicas, administrativas y político-electorales, así como la medición de las mismas. El quinto apartado presenta los resultados del estudio econométrico. La última sección presenta las conclusiones.

\section{Un marco de referencia: los determinantes de la recaudación}

La literatura que busca explicar el nivel y la composición de los impuestos distingue tres enfoques: el administrativo, el económico y el de economía política (Di John, 2006). ${ }^{4}$ El primero hace énfasis en la capacidad administrativa con la que cuenta el gobierno para recaudar (Bird y Casanegra, 1992; Tanzi, 2000; Burgess y Stern, 1993). La racionalidad del enfoque administrativo tiene paralelo con los estudios de gestión pública que enfatizan el concepto de capacidad institucional gubernamental, como se explica en una sección posterior. Según la perspectiva administrativa o de capacidad institucional, mientras más eficiente y mejor dotada de recursos (humanos, materiales, informáticos, legales) esté la administración tributaria, más se puede recaudar. De hecho, esta lógica es la que dio pie a la creación de administraciones tributarias independientes de las secretarías de hacienda, como el caso del SAT (Sistema de Administración Tributaria) en México en los años noventa.

El enfoque económico establece que las variables económicas explican el monto de recaudación (Hinrichs, 1966; Musgrave, 1969; Lotz y Morss, 1970). Las variables a las cuales se alude habitualmente son aquellas que reflejan el nivel de riqueza, producción o ingresos en un país, pues nos hablan de la capacidad que existe para pagar impuestos. Igualmente, este enfoque considera variables que puedan denotar la facilidad o dificultad para recaudar, como pueden ser el tamaño del sector primario en la economía, el nivel de urbanización, la relevancia de las importaciones y exportaciones, y el acceso que se tenga a otras fuentes de financiamiento. Definitivamente,

${ }^{4}$ Una revisión más amplia sobre la literatura de los determinantes de la recaudación se encuentra en Unda y Moreno, 2015. 
los indicadores económicos son útiles para identificar el nivel de recaudación potencial, pero no son suficientes para explicar el que países, estados o municipios con características económicas parecidas presenten niveles de recaudación distintos. En estos casos, el enfoque de la economía política es el que puede aportar a la explicación.

Esta línea plantea que los impuestos son sobre todo un problema político. ${ }^{5}$ Los impuestos, siendo impopulares por naturaleza, exigen cierto nivel de consentimiento y coerción (Levi, 1989), por lo que requieren de la construcción de consensos entre recaudador y contribuyente. Definir quién paga y cuánto paga (incidencia) es a todas luces un problema político. Los estudios que han adoptado esta perspectiva han sugerido variables explicativas como la historia, las organizaciones políticas, la legitimidad del Estado, el poder de los grupos de interés y la desigualdad. La perspectiva de la economía política de los impuestos enfatiza el proceso político que implica la recaudación: ese ciclo de extracción - resistencia - represión - negociación que detonan los impuestos (Tilly, 1992).

\section{Determinantes del predial en México sugeridos por la literatura}

Los trabajos que han analizado la recaudación municipal, o en específico el monto de predial recaudado, argumentan que las transferencias que reciben los municipios por parte de los gobiernos estatales o el federal desincentivan la generación de ingresos propios (Sour, 2004, 2008; Canavire y Zúñiga, 2010; Zúñiga, 2010). ${ }^{6}$

La lógica de esta hipótesis tiene mucho sentido especialmente si se considera el aumento extraordinario de participaciones (ramo 28) recibidas por los municipios a principios de la década de 1980 (véase la Gráfica 1). Aunque, en estricto sentido, las participaciones federales a estados y municipios existen desde la Primera Convención Nacional Fiscal, en 1925, no fue sino hasta 1980, con el establecimiento del Sistema Nacional de Coordinación Fiscal (SNCF), cuando éstas comenzaron a pagarse con base en el total de la recaudación de impuestos federales, es decir, basadas en el con-

${ }^{5}$ Para profundizar en el impacto que tienen las variables de corte político e institucional-fiscal sobre el desempeño fiscal de distintos países (más allá del nivel de recaudación tributaria), véase Poterba y Von Hagen, 1999; Kirchgässner, 2001.

${ }^{6}$ Sólo Sour (2008) analiza la totalidad de los municipios del país y únicamente Canavire y Zúñiga (2015) y Zúñiga (2010) se concentran en la relación entre la recaudación predial y las transferencias. Sour analiza el esfuerzo fiscal (ingresos propios) en ambos trabajos (2004 y 2008). 
cepto de recaudación federal participable (RFP). El SNCF se puede entender como un gran acuerdo en el que los estados, principalmente, ceden al gobierno federal la potestad de sus impuestos a cambio de que luego se les "participe" de la recaudación de impuestos federales, como el impuesto sobre la renta (ISR), el impuesto especial sobre producción y servicios (IEPS) y el impuesto al valor agregado (IVA).

\section{Gráfica 1}

Transferencias a municipios

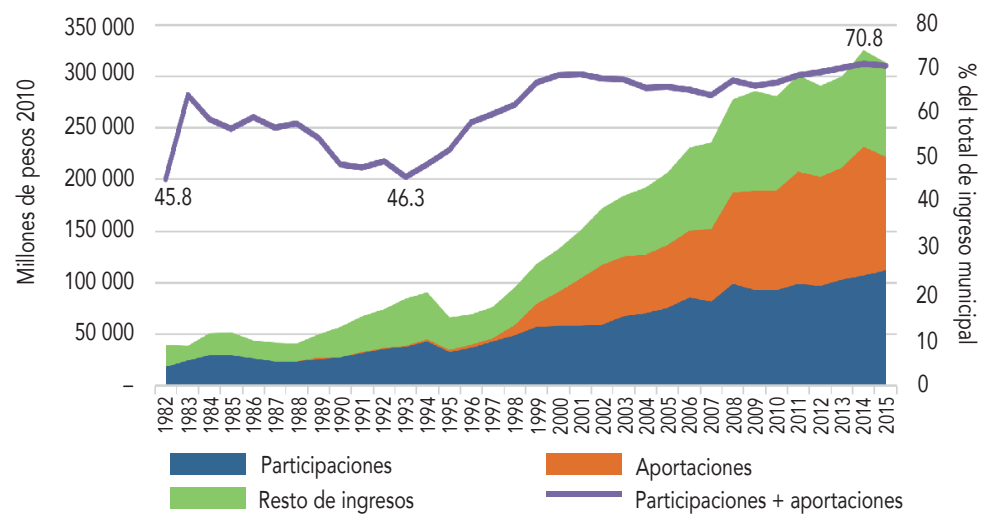

Fuente: Elaboración propia con datos de INEGI (1990), Finanzas públicas estatales y municipales, https://www.inegi.org.mx/temas/finanzas/

El segundo tipo de transferencias federales a estados y municipios son las aportaciones del ramo 33, las cuales se crearon con la reforma a la Ley de Coordinación Fiscal (LCF) de 1997 y comenzaron a operar en 1998. Las aportaciones, a diferencia de las participaciones, son transferencias de recursos federales a estados y municipios, que deben aplicarse, obligatoriamente, a financiar rubros determinados de gasto. Es decir, se trata de transferencias condicionadas. En la Gráfica 1 se muestra el crecimiento que han tenido las transferencias y la proporción de éstas dentro del total de los ingresos municipales. En 1982 las transferencias aportaban 45.8\% del ingreso; en la actualidad $71 \%$ del mismo provienen de las transferencias federales.

Debido a la evidente dependencia del municipio mexicano respecto a las transferencias (desequilibrio fiscal vertical) y a lo sugerido en estudios 
previos, este trabajo evaluará si las participaciones y las aportaciones se correlacionan negativamente o no con la recaudación predial municipal. Pero antes de presentar el estudio estadístico y sus resultados, conviene explicar la evolución del predial y el marco legal en que se ha desarrollado este impuesto en las últimas décadas.

\section{Reformas y programas federales para mejorar el desempeño del predial, 1982-2013}

En aras de la descentralización fiscal y con un especial interés por darle mayor autonomía económica al municipio (Silva-Herzog, 1982), el gobierno federal reformó el artículo 115 constitucional en 1982 para otorgarle la potestad sobre los impuestos inmobiliarios al municipio y clarificar cuáles eran sus responsabilidades de gasto. Sin embargo, para fines de los años ochenta la reforma todavía no rendía frutos; la recaudación predial estaba estancada. Si bien los municipios adquirieron la capacidad de cobrar el predial, no contaban con la infraestructura técnica y administrativa para hacerse cargo del impuesto y mejorar su productividad (Santana, 2000, p. 19, en Unda y Moreno, 2015, p. 54); lo que en la valoración de Merino (2004) corresponde a contar con un mal diseño institucional en el que las reformas aumentaron las obligaciones de los municipios, pero no conllevaron las reglas y los incentivos correctos para poder cumplir con dichas funciones.

Para finales de los ochenta el gobierno federal lanzó un programa a través del Banco Nacional de Obras y Servicios (Banobras), un banco de desarrollo. El programa consistía en dar apoyo crediticio a los gobiernos estatales y municipales para mejorar los catastros. ${ }^{7}$

En 1991 el gobierno federal buscaba impulsar la recaudación predial modificando la LCF, la cual, entre otras cosas, pauta la relación entre los tres niveles de gobierno en materia fiscal y determina, por ejemplo, cómo se deben repartir los recursos fiscales. En concreto, la ley se modificó para incluir el monto de recaudación predial como una de las variables a considerar en la fórmula de reparto a los municipios de las participaciones federales del Fondo de Fomento Municipal (FFM). De este modo, el gobierno federal puso en la mesa un incentivo: el incremento en la recaudación predial tendrá impacto en lo que el municipio reciba de participaciones federales por concepto del FFM.

${ }^{7}$ Ordoño, Azpeitia y González (1997) plantean las ventajas de actualizar y modernizar los catastros para aumentar la recaudación predial. 
A principios de los años noventa también se implementó un programa que buscaba apoyar la modernización de los catastros. El Programa de 100 Ciudades estaba a cargo de la Secretaría de Desarrollo Social (Sedesol) y entre sus objetivos estaba regularizar el uso de suelo y la administración urbana. Así, a través de estímulos financieros a los municipios, se buscaba continuar con las acciones iniciadas por Banobras y lograr la modernización catastral. ${ }^{8}$

El artículo 115 constitucional fue reformado de nuevo en 1999. Aunque desde antes se percibían los vacíos que había dejado la reforma de 1982, no fue sino hasta 1997 que la conformación del congreso permitió hacer reformas constitucionales con mayor facilidad.

Así, las modificaciones realizadas en 1999 establecen con mayor claridad las funciones públicas que son responsabilidad de los municipios (fracción III); otorgan a los ayuntamientos la capacidad de proponer a las legislaturas las cuotas, tarifas y tablas de valores de suelo y construcciones (fracción IV); y se establece que antes del ejercicio fiscal 2012 las legislaturas, en coordinación con los municipios, adopten medidas conducentes a que los valores catastrales sean equiparables con los valores de mercado (transitorio quinto) (Santana y Sedas, 1999, pp. 30-32). Con estas reformas, al menos legalmente, se buscó dar más capacidades al municipio para que pudiera tomar las riendas del impuesto predial, recaudar más, y con ello contar con mayor autonomía financiera.

En 2007, de nuevo la LCF fue reformada. La lógica de la reforma era muy similar a la que se planteó en 1991. La recaudación predial y los derechos de agua cobrados por los municipios se convirtieron en componentes de la fórmula de reparto del Fondo General de Participaciones (FGP), que es el fondo principal de recursos participables para estados y municipios.

El gobierno federal volvió, en 2007, a idear un programa para apoyar la mejora de los catastros y creó el Programa de Apoyo a la Modernización de los Catastros y de los Registros de la Propiedad, el cual tenía el fin de dar mayor certeza jurídica a la propiedad inmueble y fortalecer los ingresos inmobiliarios de los municipios.

Por último, la LCF volvió a ser reformada en diciembre de 2013. Los cambios buscaban incentivar la recaudación predial, pero por medios distintos a los usados anteriormente (el predial como componente de la fórmu-

${ }^{8}$ Los programas de modernización catastral impulsados por Banobras, Sedesol y la Secretaría de Hacienda y Crédito Público (SHCP) hacia 1997 habían tenido resultados módicos con respecto a sus objetivos planteados: 1) fortalecer las haciendas municipales, y 2) aportar herramientas e instrumentos indispensables para la planeación del desarrollo urbano. Y es que dichos programas sufrieron un recorte de más del 50\% entre 1995 y 1997 (Banobras, 1997).

Estudios Demográficos y Urbanos, vol. 36, núm. 1 (106), enero-abril, 2021, pp. 49-88 http://dx.doi.org/10.24201/edu.v36i1.1871 
la de reparto del FFM y FGP). Ahora el municipio puede recibir un monto mayor de participaciones si éste firma convenios con el gobierno estatal para que se encargue de la administración predial. Puesto de otro modo: se incentiva que el municipio ceda su capacidad de administrar el predial al siguiente nivel de gobierno, lo que deja ver una intención de recentralización fiscal por parte del gobierno federal.

Las reformas y programas implementados en las últimas tres décadas, tanto aquellos que han buscado una mayor autonomía fiscal municipal como los que han tratado de aumentar la recaudación predial en particular, han sido muy poco eficaces. La Gráfica 2 nos da una idea de lo poco que se ha avanzado en la descentralización fiscal por el lado del ingreso. Los gobiernos municipales (y estatales) en México son los que contribuyen en menor proporción al ingreso tributario del país en comparación con los países latinoamericanos.

\section{Gráfica 2}

Composición de los ingresos tributarios por nivel de gobierno, 2013

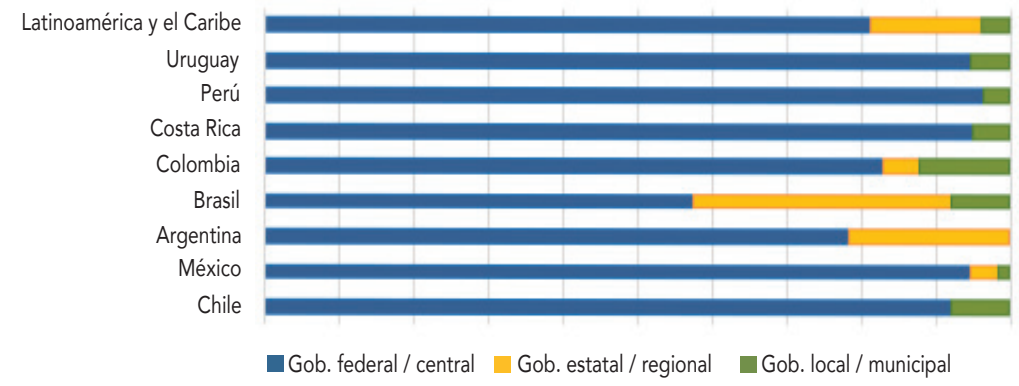

Fuente: Elaboración propia con datos de OCDE. https://stats.oecd.org/Index.aspx? DataSetCode $=$ REV

\section{Planteamiento del estudio estadístico}

A partir del marco teórico planteado con anterioridad, este trabajo busca valorar el poder explicativo que tienen las distintas variables de corte económico, administrativo y político-electoral sobre la recaudación predial. Esto se hace mediante un modelo econométrico basado en datos tipo panel, donde las estimaciones se realizan a través de un modelo de efectos fijos. $\mathrm{La}$ 
base de datos construida para esto se integra con datos a nivel municipal (2447 municipios) $)^{9}$ y durante el período 1990-2010. Se tienen 46562 observaciones de la variable dependiente (municipio.año).

\section{Cuadro 1}

Variables para el modelo de estimación de recaudación predial municipal

\begin{tabular}{ll}
\hline \multicolumn{1}{c}{ Variable } & \multicolumn{1}{c}{ Nombre } \\
\hline Dependiente & Predial per cápita municipal \\
Independiente & Determinantes económicos \\
Independiente & Determinantes político-electorales \\
Independiente & Determinantes administrativos \\
\hline
\end{tabular}

Fuente: Elaboración propia.

La variable dependiente se mide en términos del predial per cápita. Se considera, sin embargo, que la mejor manera de medir esta variable sería: recaudación predial municipal entre el valor catastral de todas las cuentas del municipio; es decir, lo recaudado entre la base tributaria. Esta medición reflejaría en sí la tasa de extracción tributaria por predial en cada municipio y dejaría ver el esfuerzo que están haciendo los municipios neutralizando el efecto de la variación en los valores catastrales que de una manera dada existe entre los municipios (el mismo metro cuadrado de vivienda vale más en la Ciudad de México que en Tuxtla Gutiérrez). Pero no hay manera de obtener los datos sobre el valor catastral de todos los predios que conforman cada municipio del país.

También se consideró medir la variable dependiente de otra forma: la recaudación predial del municipio entre el número de cuentas prediales con que cuenta el municipio, lo que daría una idea de la productividad recaudatoria promedio por cuenta. Una de las debilidades de una medición así sería que dejaría ver con buenos ojos a municipios ineficientes que registran menos cuentas simplemente porque no controlan todo el universo de cuentas prediales. Sin embargo, no se logró que las autoridades hacendarias proporcionaran el dato sobre el número de cuentas, a pesar de que este tipo de datos ha sido compilado por la Unidad de Coordinación de Entidades Federativas (UCEF) de la Secretaría de Hacienda y Crédito Público (SHCP) des-

${ }^{9}$ Los municipios mexicanos en la actualidad son 2447 . Un porcentaje menor de municipios, en determinados años, o no reporta al INEGI (nuestra fuente) su recaudación predial por cuestiones poco claras, o no cobra el impuesto. A partir de nuestra fuente no es posible diferenciar entre uno y otro tipo de municipios. 
de 1992, como parte de la información pedida a los municipios para poder aplicar las fórmulas de reparto para el FFM y, posteriormente, para el FGP.

\section{Determinantes económicos del predial municipal}

La premisa detrás de este enfoque es que los factores económicos determinan el nivel de recaudación. Siguiendo esta lógica, la variable que denotaría con mayor precisión el potencial recaudatorio sería la sumatoria de los valores catastrales, pero como se mencionó antes, los catastros no hacen pública esa información.

Así, para medir la situación económica de los municipios se utilizarán las siguientes variables socioeconómicas disponibles: población del municipio, porcentaje de la población municipal analfabeta, porcentaje de la población municipal en pobreza de patrimonio, e índice de Gini municipal. ${ }^{10}$ Ya que el nivel de desarrollo económico denota tanto la capacidad de pago como la de recaudación, se considera que los indicadores que reflejan las carencias del capital humano (proporción de analfabetos), la pobreza del municipio y su nivel de desigualdad, son buenos proxy para medir el nivel económico del municipio. Esto a falta también de cálculos longitudinales sobre el PIB municipal para todos los municipios del país. La población del municipio se considera un indicador válido para captar de alguna forma la "ruralidad" del municipio, que, como plantean y concluyen Unda y Moreno (2015, pp. 62-63, 65-67), está negativamente correlacionada con la recaudación predial. Y también se supone un indicador útil pues los niveles de urbanización están relacionados positivamente con indicadores de bienestar mayores (World Bank, 2009, pp. 62-66).

Otro corte de variables que sirven para comprobar el poder explicativo de los determinantes económicos son aquellas que reflejan el tamaño de los recursos alternos con los que el municipio cuenta. Lo que ha sugerido la literatura es que las transferencias intergubernamentales se correlacionan negativamente con la recaudación del municipio. En ese sentido, pondremos a prueba si empíricamente esto se sostiene. Los indicadores que se

\footnotetext{
${ }^{10}$ Los primeros dos indicadores tienen fuente en los censos y conteos de población realizados por el INEGI en 1990, 1995, 2000, 2005 y 2010. Los últimos dos indicadores se tomaron de estimaciones del Coneval (Consejo Nacional para la Evaluación de la Política Social) con base en las ENIGH de 1992, 2000 y 2010, los Censos de Población y Vivienda 1990 y 2000, y la muestra del Censo de Población y Vivienda 2010. En los casos en que la información no está disponible anualmente, se utilizó la tasa media de crecimiento anual del quinquenio para calcular los datos anuales.
} 
consideraron para este efecto son: participaciones federales a municipios per cápita, aportaciones federales ${ }^{11}$ a municipios per cápita, e ingresos no tributarios per cápita. ${ }^{12}$

\section{Determinantes políticos del predial municipal}

Nuestro marco teórico de referencia muestra que existe otro corte de variables que explican el desempeño recaudatorio. Se parte de la idea de que los impuestos son un problema político. Decidir quién paga y cuánto paga, por ejemplo, son preguntas que están sujetas a cálculos políticos. Las autoridades municipales, ante la disyuntiva de aumentar los valores catastrales y equipararlos a los valores de mercado, sopesarán el costo político que ello les implique. Lo mismo sucedería ante la disyuntiva de aplicar cualquier medida que implique el aumento de la carga a los contribuyentes (votantes), como incrementar las tasas prediales, hacer las tasas más progresivas, o tener programas de actualización constante de valores.

Este estudio considera dos tipos de variables políticas: las electorales y las de desempeño del gobierno. El primer corte de variables se mide a través de indicadores de resultados electorales en los municipios de México de 1990 a $2010 .^{13}$

Las variables políticas electorales son dos: la competencia electoral en el municipio y la congruencia partidista entre los órdenes de gobierno estatal y municipal. La primera se mide como margen de victoria entre el primer y el segundo lugar. Y suponemos que mientras mayor es la percepción de riesgo de perder las elecciones (mayor competencia política), se tomarán menos decisiones impopulares, como aumentar el predial.

La segunda variable político-electoral es la congruencia partidista (que el alcalde y el gobernador pertenezcan al mismo o a diferente partido político). Según las entrevistas realizadas por esta autora con los funcionarios

${ }^{11}$ Cabe indicar que, aunque las aportaciones fueron formalmente creadas en 1998, los municipios recibían desde antes transferencias federales de los convenios de desarrollo social provenientes del ramo 26. Es por ello que los montos transferidos a los municipios por estos conceptos antes de 1998 están incluidos en la base de datos que da pie al análisis econométrico.

${ }^{12}$ La fuente para estas variables de finanzas públicas es: INEGI, Estadisticas de finanzas públicas municipales (se ofrecen de manera anual y para todos los municipios del país). Disponible en: https://www.inegi.org.mx/temas/finanzas/

${ }^{13}$ En aquellas elecciones municipales en que los contendientes representan alianzas de distintos partidos, el criterio para etiquetar a la alianza fue denominarla bajo el partido político más grande (PRI, PAN o PRD). En los casos de alianzas entre partidos grandes, como PRDPAN, se etiquetó de acuerdo al partido que en el estado haya ganado más votos en la última elección. 
del catastro y las tesorerías, se encontró que el ejecutivo y el legislativo estatal son actores relevantes para determinar la normatividad del predial. ${ }^{14}$ Son actores con poder de veto de facto. Como se explicó antes, desde 1999 el artículo 115 constitucional otorga a los ayuntamientos la capacidad de proponer a las legislaturas las cuotas, tarifas y tablas de valores de suelo y construcciones, pero la última palabra la tiene la legislatura estatal. ${ }^{15}$

De este modo, se supone que en caso de que un municipio quiera modificar los valores catastrales al alza, o aumentar las cuotas y tarifas para poder elevar su recaudación predial, éste estará supeditado a la voluntad de los poderes estatales. Se propone aquí que es más probable la negativa a las iniciativas recaudatorias municipales cuando el partido de los presidentes municipales no coincida con el del gobernador.

Al analizar los datos cuantitativamente también se pone atención al comportamiento que presenten cada uno de los partidos políticos y la variable dependiente. Con ello se aprecia si algún partido en específico tiende a recaudar más que otros. Pero no se espera ninguna correlación en especial debido a que los partidos mexicanos, en términos ideológicos y quizás aún más a nivel local, están difusamente delimitados.

El segundo tipo de variables políticas tiene que ver con el desempeño del gobierno municipal en términos de gasto. Se parte de la idea de que el contribuyente tiene cierto margen de decisión ante la disyuntiva de pagar o no impuestos. El supuesto es que su decisión dependerá de qué tanto perciba que le conviene pagar tomando en consideración lo que recibe a cambio de sus impuestos en bienes y servicios públicos. El contribuyente también considerará la capacidad de control y coerción con que cuenten las autoridades. Mientras menos riesgo perciba de ser sancionado por evadir, más lo hará. En sí, la capacidad de control y coerción de las autoridades impositivas refleja la capacidad institucional de las mismas.

La racionalidad detrás de estas variables sobre el desempeño gubernamental está inspirada en la propuesta de Margaret Levi (1989) sobre el concepto de quasi-voluntary compliance o cumplimiento casi voluntario. Según ella lo explica, una combinación de factores hace que el gobierno sea capaz de cobrar impuestos. Los gobiernos que tienen la capacidad de

${ }^{14}$ Como parte de este proyecto de investigación se llevó a cabo también un estudio de casos. Los resultados se encuentran en Unda, 2018.

${ }^{15}$ Con base en lo anterior, sería ideal contar con una tercera variable: coincidencia entre la afiliación política del alcalde y la de la mayoría de la legislatura estatal. Pero los datos de los resultados electorales que permitirían construir esta variable no están disponibles para el período de tiempo que se analiza en este trabajo. Para consultar trabajos en los que esta variable ha sido medida en estudios relacionados con el endeudamiento y la dependencia financiera de los municipios, véase Ibarra, González y Sotres, 2013; Ramírez, 2003. 
propiciar un cumplimiento casi voluntario recaudarán más que los que no la tengan. El gobierno, ante la imposibilidad de vigilar a cada uno de los contribuyentes (por el costo tan alto del control que esto implicaría), no puede confiar sólo en el aspecto sancionatorio y de control para poder recaudar. También tiene que poder convencer a los contribuyentes haciéndoles ver que tienen algo que ganar del intercambio de pago de impuestos por servicios y bienes públicos. Entonces, el pago de impuestos es voluntario en la medida en que algunos contribuyentes encuentren conveniente pagar, pero también en función de que los gobiernos utilicen su capacidad de control y sanción, ya que siempre existirá algún polizón (free-rider) entre los contribuyentes.

El análisis cuantitativo, entonces, medirá la "capacidad de los gobiernos municipales de convencer" a los contribuyentes con tres variables que se proponen como proxys de medición del desempeño del gobierno. Un gobierno municipal tiene múltiples conceptos de gasto, pero uno de los más relevantes para este estudio es la inversión en obra pública. Este concepto de gasto es el que quizá exprese mejor la transformación de los impuestos en bienes tangibles y visibles para los ciudadanos. Suponemos que mientras mayor gasto en inversión per cápita, mayor "convencimiento" por parte del contribuyente para pagar.

En cambio, partimos de una hipótesis contraria para el caso del gasto corriente. Es decir, se espera una correlación negativa entre el gasto corriente per cápita y la recaudación predial. Si bien el gasto corriente (que en su mayor parte se dedica al pago de sueldos y salarios de los funcionarios públicos) es necesario, pues permite el funcionamiento de las tareas del gobierno municipal, no es tan fácilmente traducido por el contribuyente como parte de lo que el gobierno debe de dar a cambio de los impuestos, como sí lo es el alumbrado, el estado de las calles y la infraestructura municipal en general. Además, es factible que el crecimiento del gasto corriente se explique más por la necesidad de los gobiernos entrantes de pagar con puestos en la administración municipal a quienes los apoyaron en la campaña electoral, como encuentra Moreno (2007, p. 429), que por perseguir objetivos de eficiencia y eficacia en el desempeño del aparato municipal. ${ }^{16}$

En la misma lógica en que se plantea el comportamiento entre la inversión pública y la recaudación predial per cápita, se propone una tercera variable: aquella que nos mida el desempeño de los gobiernos en proveer

${ }^{16}$ Las variables de inversión y gasto corriente per cápita municipal se construyeron también a partir de: INEGI, Estadisticas de finanzas públicas municipales. Disponible en: https:// www.inegi.org.mx/temas/finanzas/ 
servicios de agua, luz eléctrica, y drenaje y desagüe. ${ }^{17}$ Esto porque la entrega de dichos servicios es responsabilidad de los municipios ${ }^{18}$ (aunque pueden coordinarse y apoyarse en otro nivel de gobierno) y por la disponibilidad amplia y confiable de estos datos.

Cabe enfatizar que las variables políticas sobre el desempeño del gobierno presentan una imprecisión en su medición, misma que es inherente a la naturaleza del tipo de conceptos que se intenta medir. Los contribuyentes, por ejemplo, pueden "percibir" que un gobierno está haciendo su trabajo mejor que el anterior, a pesar de que en realidad esto no sea así o viceversa. El punto es que la percepción del ciudadano (contribuyente) sobre el desempeño de su gobierno puede no ser "correcta" debido a que existen diversos factores que pueden distorsionar la percepción. Tal es el caso de las campañas mediáticas, por ejemplo, que pueden hacer cambiar la percepción de la ciudadanía sin que realmente exista un cambio real o de fondo en el desempeño de dicho gobierno. Sin embargo, a pesar de la imprecisión que puedan tener estas variables para medir el desempeño del gobierno y lo que realmente interpretan los ciudadanos de estas variables y del gobierno en general, consideramos que es un indicador aproximado suficiente para comprobar la importancia que tiene el desempeño del gobierno para mejorar el cumplimiento tributario.

\section{Determinantes administrativos o de capacidad institucional del predial}

La literatura sobre los determinantes de la recaudación utiliza el término "capacidad administrativa" para referirse al conjunto de habilidades de la administración tributaria para lograr la recaudación de impuestos de una manera eficiente y eficaz. Este término es equivalente al concepto de capacidad institucional que se utiliza en el campo de la administración pública, mismo que aquí explicamos y utilizamos como variable explicativa.

La capacidad institucional refleja "la habilidad de las instituciones en su conjunto, desde los individuos a través de las organizaciones, la legislación y los instrumentos de política utilizados para desarrollar una tarea"

${ }^{17}$ La fuente de estas variables son los censos y conteos del INEGI que miden la cobertura de servicios básicos a la vivienda. Disponible en: http://www.beta.inegi.org.mx/proyectos/ ccpv/cpvsh/

${ }^{18}$ En las reformas al artículo 115 constitucional de 1982 y 1999 se establecieron las responsabilidades del municipio, las cuales abarcan: provisión de agua potable; drenaje, alcantarillado, tratamiento y disposición de aguas residuales; alumbrado público; limpia, recolección, traslado, tratamiento y disposición final de residuos; mercados y centrales de abasto; panteones; rastro; calles, parques y jardines y su equipamiento; seguridad pública, como policía preventiva municipal y de tránsito. 
(Meene y Brown, 2007, p. 2, citado en Carrera y Rivera, 2012, p. 16). En este sentido, la construcción de la capacidad institucional consiste en el desarrollo de las habilidades necesarias para que las organizaciones públicas logren determinados objetivos de política, como lo advierte Mizrahi (2004).

El concepto de "construcción de la capacidad institucional" es útil aquí, puesto que hace hincapié en los componentes que conforman la capacidad institucional; es decir, qué es lo que hace que un orden de gobierno, nacional o subnacional, tenga la capacidad necesaria para lograr sus objetivos. ${ }^{19} \mathrm{~A}$ pesar de que no existen definiciones precisas sobre cuáles son estos componentes, se han sugerido algunas categorías generales. Por ejemplo, para Daud, Alias y Muthuveerappan (2008), los componentes de la capacidad institucional pueden ser: i) el desarrollo de los recursos humanos, proceso en el que se le dota a las personas del conocimiento y las habilidades para desempeñarse con eficacia; ii) el desarrollo de la organización, que considera las estructuras de gestión, así como los procesos y procedimientos internos y externos; iii) el marco jurídico e institucional, donde se consideran los cambios legales y reglamentarios que les permiten a las organizaciones, instituciones y organismos de todos los niveles y sectores, mejorar sus capacidades; y $i v$ ) el desarrollo de las funciones de apoyo, que concentran las tecnologías de la información y comunicación para aumentar su productividad, así como la adopción de tecnologías que les permitan desarrollar y administrar sus bancos de información.

Muchos de estos componentes de la capacidad institucional son de difícil medición para un estudio longitudinal como éste (abarca dos décadas), que incluye a todos los municipios del país. ${ }^{20}$ Sin embargo, hay algunos indicadores que se pueden considerar buenas aproximaciones a la capacidad institucional de los municipios mexicanos para cobrar el predial.

Para plantear las variables de capacidad institucional, ${ }^{21}$ se tomaron como base los datos que ofrecen distintas encuestas y censos a gobiernos

${ }^{19}$ Existen otras definiciones que están orientadas más al alcance de los resultados y, en consecuencia, al medir la capacidad institucional se basan en indicadores de resultados; determinan, por ejemplo, que un gobierno tiene una mayor capacidad institucional si logra la reducción de la pobreza o si recauda más. Sin embargo, el énfasis de este tipo de definiciones no es muy útil cuando se quiere entender por qué unos municipios tienen mayor capacidad institucional que otros.

${ }^{20}$ Para poder medir la capacidad institucional municipal para cobrar el predial a mayor cabalidad se requiere de un estudio de caso. Una primera contribución a la medición de capacidad institucional municipal se encuentra en Unda, 2018.

${ }^{21}$ Encuesta Nacional sobre Desarrollo Institucional Municipal, 2000; Encuesta Nacional a Presidentes Municipales sobre Desarrollo Social, 2002; Encuesta Nacional de Gobiernos Municipales, 2004; Encuesta Nacional de Gobierno, Seguridad Pública y Justicia, 2009; Censo Nacional de Gobiernos Municipales y Delegacionales, 2011; Censo Nacional de Gobiernos Municipales y Delegacionales, 2013. 
municipales, pues recaban datos sobre distintos temas como: $i$ ) recursos humanos, ii) recursos legales, iii) impuesto predial, iv) servicios públicos municipales, $v$ ) recursos materiales y electrónicos, y vi) trámites y servicios. A pesar de que es mucha la información que obtienen estas encuestas y censos, sólo algunos indicadores son útiles como mediciones aproximadas de la capacidad institucional de un municipio para el cobro del predial, ya que para algunos indicadores no existe continuidad en su levantamiento y manera de medición a través del tiempo. Estos indicadores sólo están disponibles para algunos años de la década de 2000.

Las variables de capacidad institucional planteadas son de dos tipos: de recursos humanos y sobre el predial. Se eligieron cuatro variables institucionales: la proporción de (i) los empleados de base en el ayuntamiento se incluye como variable independiente, pues según varios entrevistados, ${ }^{22}$ este personal (sindicalizado en su mayoría) se reconoce como ineficiente y merma la capacidad institucional del aparato municipal. Por el contrario, (ii) el personal de confianza es en quien recae la iniciativa y mayor parte del trabajo. Se espera una correlación negativa en el primero y positiva en el segundo. Las últimas dos variables de capacidad institucional miden (iii) cuándo se hizo la última actualización de valores en el municipio, y (iv) cuándo se actualizó por última vez el padrón catastral. Estas dos variables toman valores de tres si se actualizaron el año previo, de dos si se actualizaron dos años atrás, y de uno si se actualizaron hace tres años o nunca. Mientras más atrás se haya realizado una actualización en los valores catastrales, los valores serán más bajos y, por consecuencia, menor la recaudación.

\section{Resultados del estudio estadístico}

La primera parte de este apartado sintetiza algunos hallazgos generales que describen la situación de los municipios en México con respecto a su predial y otras variables. La gráfica en esta sección muestra la media de cada categoría y una desviación estándar de cada lado de la media. La segunda parte se concentra en los resultados de los modelos de regresión planteados.

${ }^{22}$ Como se mencionó antes, este proyecto de investigación se diseñó considerando dos tipos de análisis, cuantitativo y cualitativo, necesarios para poder responder a la pregunta: ¿qué determina la variación de la recaudación predial en los municipios de México de 1990 a 2010? Los resultados del segundo tipo de análisis, el estudio de caso, se encuentran en Unda, 2018. 


\section{Cuadro 2}

Resumen de variables independientes propuestas

\begin{tabular}{|c|c|c|}
\hline \multicolumn{3}{|c|}{ Variables económicas } \\
\hline $\begin{array}{l}\text { Condiciones } \\
\text { socioeconómicas }\end{array}$ & $\begin{array}{l}\text { - Población municipal } \\
\text { - Porcentaje de la población municipal en } \\
\text { pobreza de patrimonio } \\
\text { - Indice de Gini municipal }\end{array}$ & $\begin{array}{l}\text { Disponible: 1990, } \\
\text { 1995, 2000, 2005, } \\
2010\end{array}$ \\
\hline $\begin{array}{l}\text { Recursos } \\
\text { alternos }\end{array}$ & $\begin{array}{l}\text { - Participaciones federales a municipios } \\
\text { per cápita } \\
\text { - Aportaciones federales a municipios } \\
\text { per cápita } \\
\text { - Ingresos no tributarios per cápita }\end{array}$ & $\begin{array}{l}\text { Disponible: } 1989- \\
2013\end{array}$ \\
\hline \multicolumn{3}{|c|}{ Variables políticas electorales } \\
\hline $\begin{array}{l}\text { Competencia } \\
\text { electoral }\end{array}$ & $\begin{array}{l}\text { - Margen de victoria del alcalde sobre } \\
\text { el segundo lugar }\end{array}$ & $\begin{array}{l}\text { Disponible: } 1989- \\
2013\end{array}$ \\
\hline $\begin{array}{l}\text { Congruencia } \\
\text { partidista }\end{array}$ & $\begin{array}{l}\text { - Congruencia entre el partido en la presi- } \\
\text { dencia municipal y la gubernatura estatal } \\
\text { (variable dicotómica) }\end{array}$ & $\begin{array}{l}\text { Disponible: 1989- } \\
2013\end{array}$ \\
\hline
\end{tabular}

Variables políticas sobre desempeño del gobierno

\begin{tabular}{|c|c|c|}
\hline $\begin{array}{l}\text { Inversión } \\
\text { pública }\end{array}$ & $\begin{array}{l}\text { - Inversión pública como porcentaje total } \\
\text { de ingresos públicos }\end{array}$ & $\begin{array}{l}\text { Disponible: } 1989- \\
2013\end{array}$ \\
\hline Gasto corriente & $\begin{array}{l}\text { - Gasto corriente como porcentaje total } \\
\text { de ingresos públicos }\end{array}$ & $\begin{array}{l}\text { Disponible: } 1989- \\
2013\end{array}$ \\
\hline $\begin{array}{l}\text { Mejora en la } \\
\text { cobertura } \\
\text { de servicios } \\
\text { en viviendas }\end{array}$ & $\begin{array}{l}\text { - Cobertura de viviendas particulares } \\
\text { habitadas con agua en la vivienda } \\
\text { - Cobertura de viviendas particulares } \\
\text { habitadas con drenaje y desagüe } \\
\text { - Cobertura de viviendas particulares } \\
\text { habitadas con electricidad }\end{array}$ & $\begin{array}{l}\text { Disponible: } 1989- \\
2013\end{array}$ \\
\hline \multicolumn{3}{|c|}{ Variables de capacidad institucional } \\
\hline $\begin{array}{l}\text { Recursos } \\
\text { humanos }\end{array}$ & $\begin{array}{l}\text { - Porcentaje de empleados del ayuntamien- } \\
\text { to de base } \\
\text { - Porcentaje de empleados del ayuntamien- } \\
\text { to de confianza }\end{array}$ & $\begin{array}{l}\text { Disponible: } 2000 \text {, } \\
2002,2004,2011 \text {, } \\
2013\end{array}$ \\
\hline Sobre predial & $\begin{array}{l}\text { - Periodicidad en la actualización } \\
\text { de valores } \\
\text { - Nivel de actualización del catastro }\end{array}$ & $\begin{array}{l}\text { Disponible: } 2000 \text {, } \\
2002,2004,2011 \text {, } \\
2013\end{array}$ \\
\hline
\end{tabular}

Nota: Al describir y justificar cada una de estas variables independientes se hizo mención individual en notas al pie sobre las referencias que originan estos datos.

Fuente: Elaboración propia. 


\section{Un primer acercamiento al predial en México}

Los datos de los veinte años de estudio muestran que, mientras más población tenga el municipio, más recaudación predial per cápita obtiene. El promedio de recaudación de los municipios de menos de 5000 habitantes es de 43 pesos, mientras que los municipios más poblados (más de un millón) recaudan 211. La recaudación entre los menos poblados (hasta 100000 habitantes, que constituyen el $92 \%$ de los municipios del país) no presenta mucha variación (lo que se representa en la longitud de las líneas horizontales). En cambio, los municipios de 100000 a 499999 habitantes llaman la atención pues tienen la dispersión más grande; es el grupo donde existe más heterogeneidad en el desempeño del predial. Recaudan, en promedio, 148 pesos. Este grupo representa el 6\% del total de municipios, pero $28 \%$ de la población. Por último, los municipios de 500000 habitantes a un millón (27 municipios en el país, pero $17 \%$ de la población) y los de más de un millón (9 municipios con $11 \%$ de la población) recaudan cantidades muy similares, 216 y 211 respectivamente.

\section{Gráfica 3}

Predial per cápita según población municipal (pesos constantes de 2010)

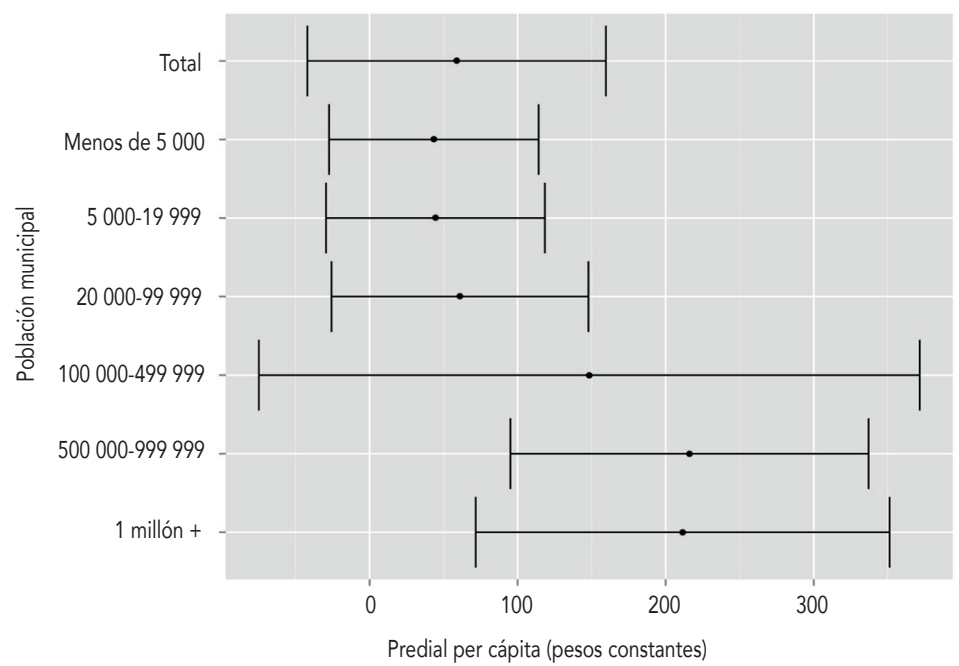

Fuente: Elaboración propia. 
La Gráfica 4 muestra la recaudación promedio por año de todos los municipios y la dispersión que existe entre ellos cada período. Un municipio típico en 1990 recaudaba 32 pesos y para 2013 alrededor de 90 pesos. La recaudación mejoró a inicios de los años noventa. Se sugiere que la recaudación bajó a partir de 1995 como producto de la crisis económica que inició ese año. Es de llamar la atención el que la dispersión en la recaudación entre municipios es mayor conforme pasa el tiempo, lo que indica que a partir del año 2000 hay más municipios que se empezaron a despegar del promedio y hacen un esfuerzo por recaudar más.

\section{Gráfica 4}

Predial per cápita anual

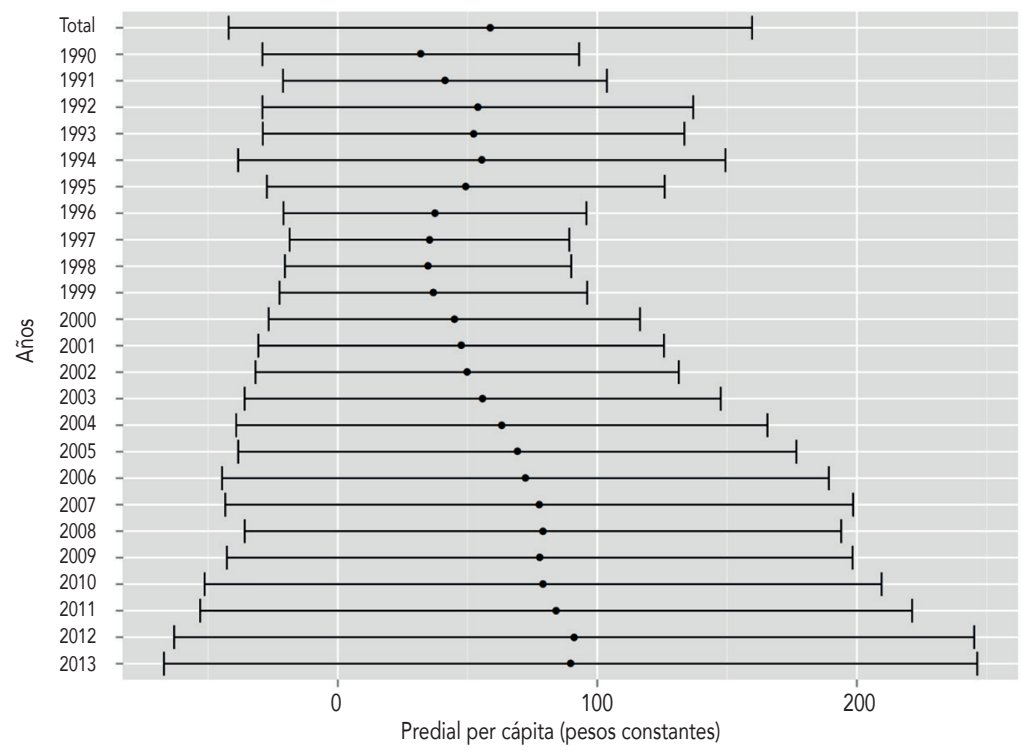

Fuente: Elaboración propia.

La Gráfica 5 muestra el promedio de recaudación municipal por estados. La recaudación predial más baja se presenta en Yucatán, Tlaxcala, Chiapas y Oaxaca, es decir, estados pobres. Las dispersiones más grandes en recaudación per cápita están en entidades como Quintana Roo, Baja California Sur, Morelos, Nayarit, Nuevo León, las cuales se distinguen por 
tener municipios outliers, que en estos casos son destinos turísticos. Quintana Roo, por ejemplo, cuenta con el segundo, tercero y cuarto lugar como mejor recaudador del país (Isla Mujeres, Solidaridad y Tulum); por su parte, Baja California Sur tiene el quinto y el decimosegundo lugar (Loreto y Los Cabos). Lo anterior sugiere que los municipios que son destinos turísticos - playas principalmente- se alejan de las características regulares de los demás municipios. Una hipótesis para explicar este comportamiento es que el valor tan alto de los inmuebles (hoteles) y la tenencia de derechos de propiedad en manos de extranjeros puede tener algo que ver con el comportamiento "disparado" en recaudación en estos municipios. Pero es algo pendiente por comprobar. La dispersión de Nuevo León, por otro lado, se explica, muy probablemente, por tener al municipio que más ha recaudado en el país durante los últimos años: San Pedro Garza García.

\section{Gráfica 5}

Predial per cápita según estados del país

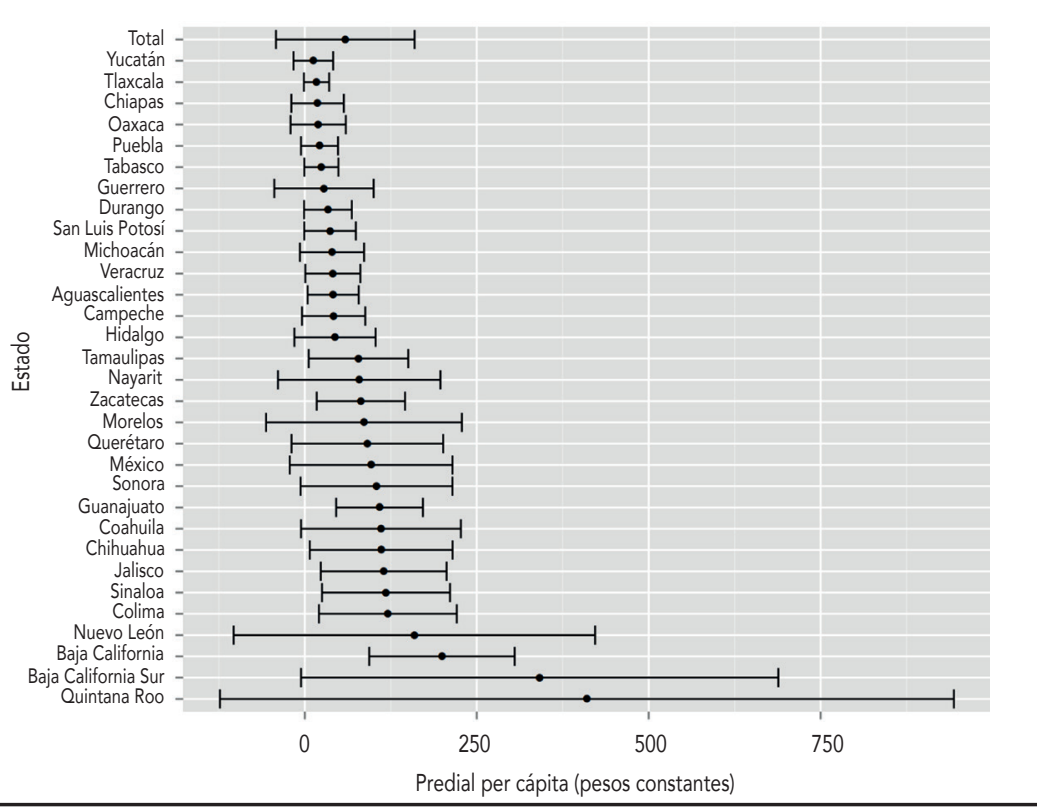

Fuente: Elaboración propia. 
La Gráfica 6 muestra la recaudación predial según el partido político que gobierna el municipio. Los datos electorales y de recaudación de veinte años revelan que los municipios bajo el gobierno del PAN (Partido Acción Nacional) recaudan más predial que los del PRI (Partido Revolucionario Institucional) o los del PRD (Partido de la Revolución Democrática). En promedio, los municipios panistas recaudan 128 pesos; y los priistas y perredistas están muy cerca del promedio nacional (59 pesos), recaudando 57 y 58 pesos en promedio. En términos de la posición ideológica partidista, uno esperaría que los partidos de izquierda prefirieran los impuestos directos (como el predial) sobre los indirectos debido al mayor potencial de progresividad de los primeros. Por el contrario, los partidos de derecha, conservadores e identificables con la clase empresarial, preferirían los impuestos indirectos pues tienden a ser más regresivos. Bajo esta lógica, de los tres partidos, uno esperaría que el PRD recaudara más en predial que los municipios gobernados por los otros dos partidos. Sin embargo, en el tema impositivo las posturas ideológicas son más bien difusas y los partidos en México convergen en adoptar posturas populistas rechazando el cobro de impuestos. ${ }^{23}$ Para muestra están las promesas electorales de eliminar el impuesto de la tenencia o no aumentar el predial, como anota Unda (2018, pp. $621,632)$. El que los municipios gobernados por el PAN recauden el doble que los gobernados por el PRI o el PRD puede deberse a que los primeros sean los municipios de mayor población y los más ricos, y/o que tengan administraciones que busquen invertir más (de ahí la necesidad de tener más recursos) y endeudarse menos.

\section{Resultados de los modelos econométricos considerando todos los municipios del país}

Los Cuadros 3 y 4 muestran los resultados de 12 modelos, los cuales algunas veces incluyen los efectos fijos para el año, el año y el estado, y el año y el municipio. ${ }^{24}$ Los modelos 7 a 12 abarcan menos observaciones ya que incluyen variables de capacidad institucional que sólo están disponibles para algunos años.

${ }^{23} \mathrm{Al}$ margen de los debates que genera la definición del término populista, en este artículo se reconoce como populista aquella medida que busca agradar al pueblo, lo que en consecuencia significa también que tales medidas buscan evitar el conflicto. Pero éste es intrínseco al problema tributario; por algo etimológicamente los impuestos sugieren imposición.

${ }^{24}$ Se aplicó la prueba de Durbin-Watson a todos los modelos con efectos fijos. En todos los casos la prueba falló al rechazar la hipótesis nula de no autocorrelación. 


\section{Gráfica 6}

Recaudación predial per cápita y partidos políticos

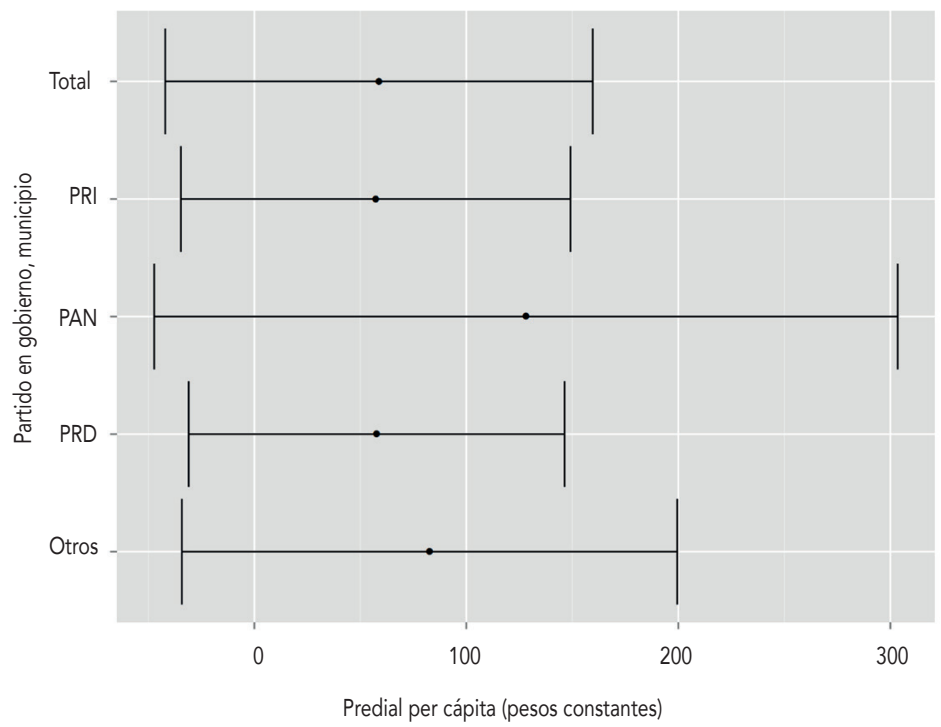

Fuente: Elaboración propia.

Los factores económicos a lo largo de todos los modelos son relevantes. Los resultados del primer modelo muestran que todas las variables económicas consideradas son estadísticamente significativas y tiene una $r$ cuadrada de 0.3 , lo cual sugiere que la variación en la recaudación es explicada en alrededor de 30\% por factores económicos. En la mayoría de los modelos, mientras menos pobreza, menos analfabetismo y más desigualdad, mayor es la recaudación. Puede ser que los municipios que recaudan más estén más poblados, sean más ricos y tengan mayor desigualdad en el ingreso.

Las variables que buscan medir el impacto de los recursos alternos en la recaudación no actúan negativamente en ella; lo que es coincidente con las conclusiones del Banco Mundial al analizar los procesos de descentralización en América Latina. ${ }^{25} \mathrm{El}$ hallazgo más consistente es que las participaciones

${ }^{25}$ Según el Banco Mundial no hay evidencia, dada la experiencia de las municipalidades en los últimos años, que soporte la hipótesis de que un incremento en las transferencias causa reducción en el nivel de recaudación de impuestos locales (World Bank and United Cities and Local Government, 2008, pp. 185-186; traducción propia). 


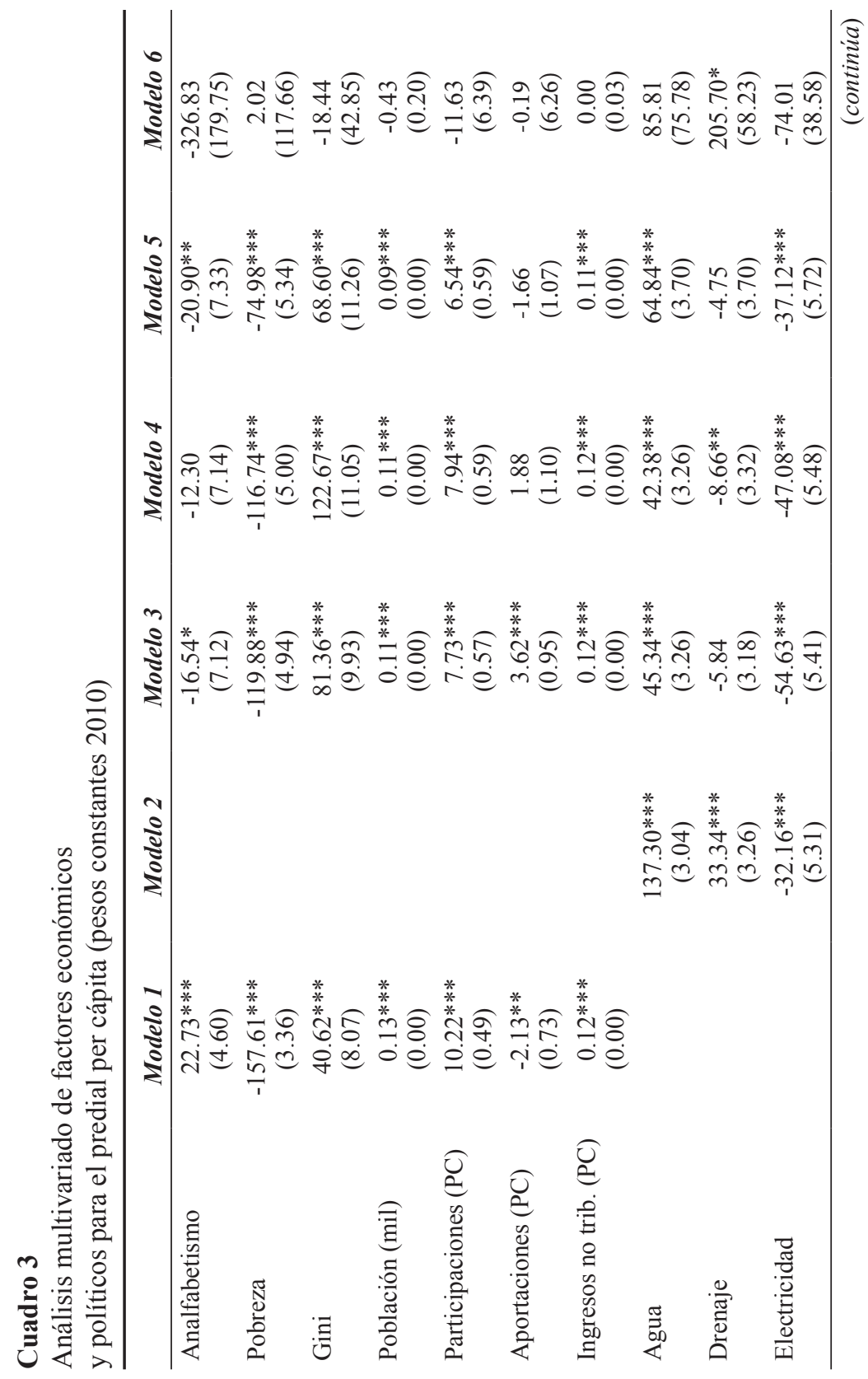




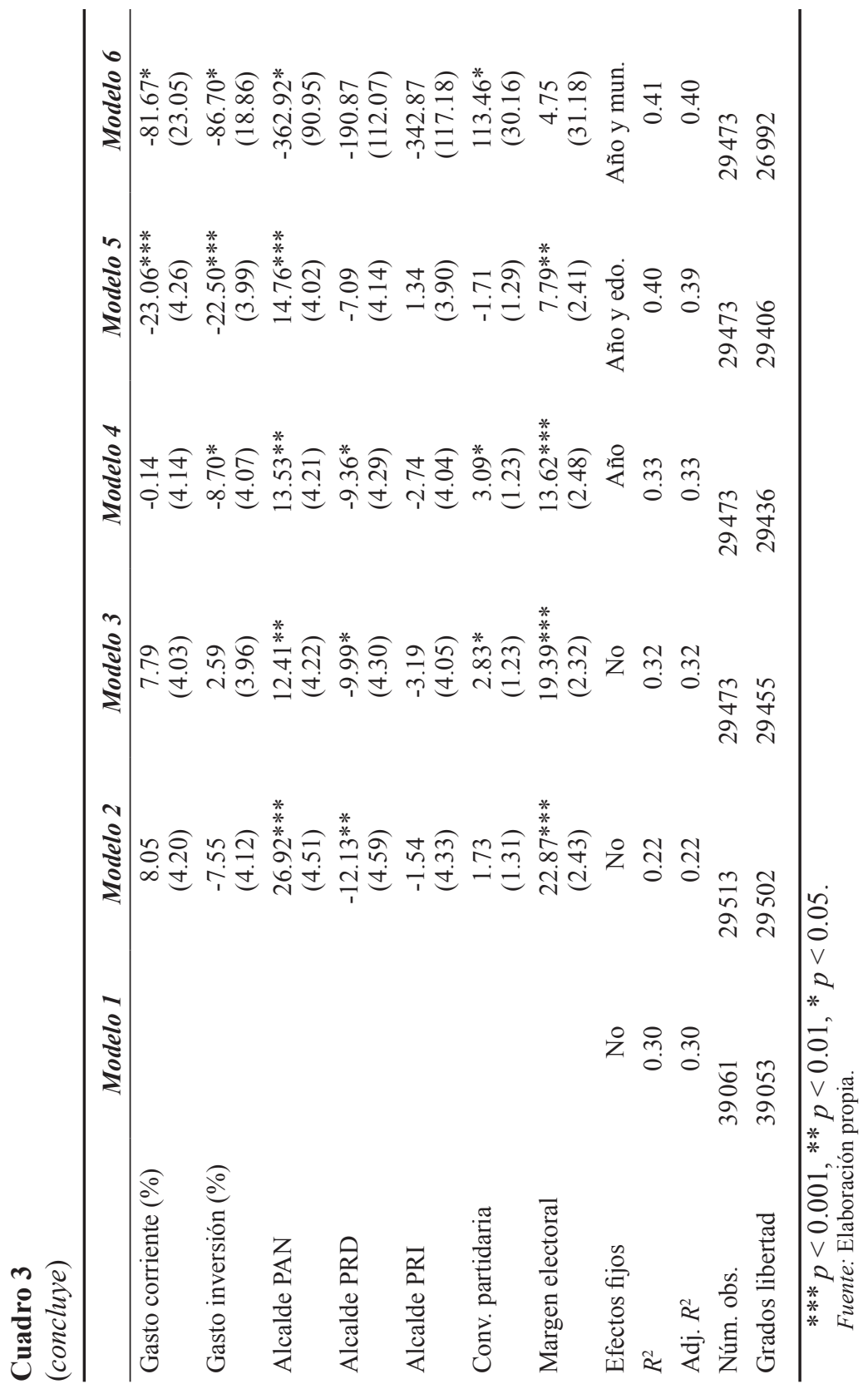




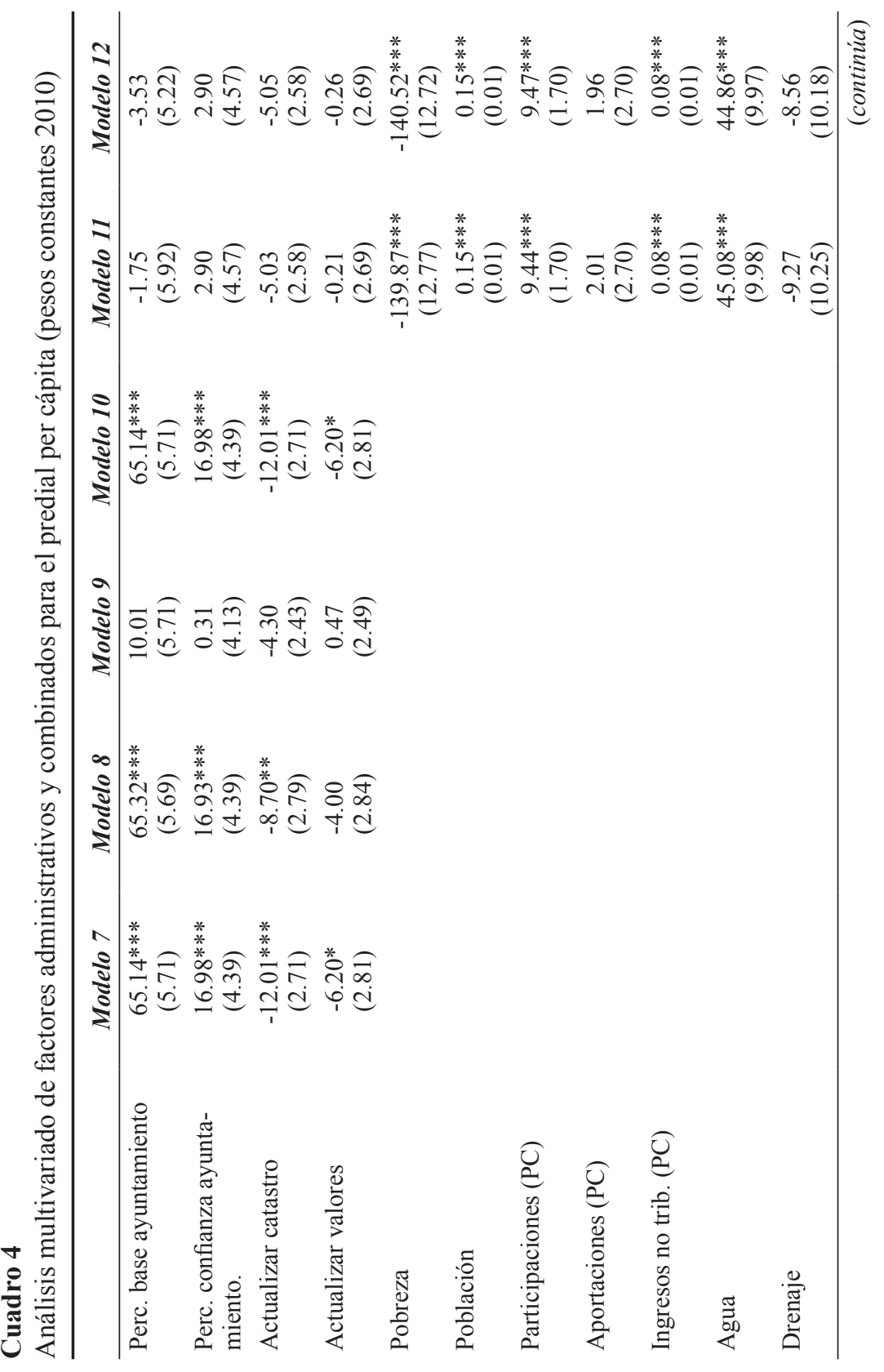




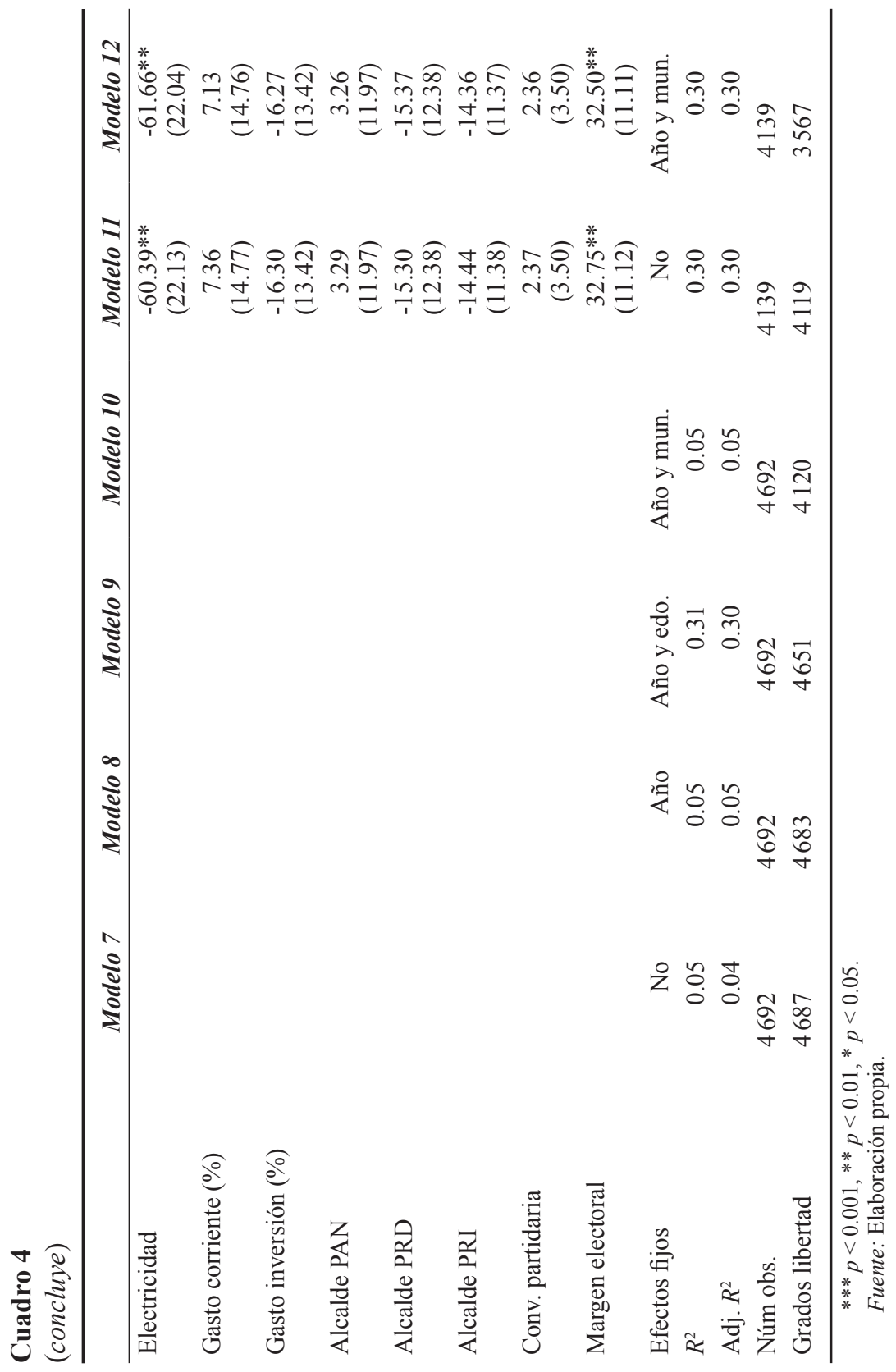


tienen una correlación positiva con la recaudación, lo que puede indicar que la fórmula de reparto de participaciones para los municipios es eficaz en no desincentivar la recaudación. Tanto la reforma al artículo 115 en 1999 como las reformas a la LCF de 1991 y 2007 podrían ser responsables de neutralizar el efecto negativo que las transferencias puedan tener en el nivel de recaudación. Con la inclusión de efectos fijos a nivel municipal (modelo 6), los coeficientes de factores económicos ya no aparecen como significativos. Esto se puede deber a que la variación entre municipios es mayor que la que existe en cada municipio a lo largo del tiempo.

Los factores políticos incluyen aquellos que: $i$ ) buscan medir qué tan eficaces son los gobiernos municipales para cumplir con sus responsabilidades y así poder "convencer" al contribuyente de cumplir, y ii) los que miden la situación político-electoral. Los hallazgos son mixtos en cuanto a las variables sobre desempeño gubernamental. Por un lado, los municipios con mayor cobertura de agua y en algunos casos de drenaje parecen recaudar más. Por otro lado, la cobertura de electricidad inexplicablemente tiene una correlación negativa. Las variables que indican si el presupuesto se gasta en gasto corriente o en inversión sólo aparecen como significativas con la inclusión de efectos fijos geográficos y, en este caso, con coeficientes negativos. Esto no es consistente con lo esperado. En la sección anterior se explicó que se esperaba una correlación positiva en los municipios que dedicaran mayor proporción de su gasto a la inversión, ya que esto podría reflejar la traducción de impuestos en bienes tangibles y visibles para los ciudadanos. El que estas variables no sean significativas y muestren signos contrarios a lo esperado, se puede deber a dos factores. Uno, las mediciones utilizadas son demasiado gruesas para poder medir el grado de satisfacción de los contribuyentes que, en caso de tenerlo, debieran ampliar el nivel de cumplimiento tributario. Dos, como se advirtió en la sección anterior, el fin de estas variables es capturar el nivel de satisfacción de los contribuyentes respecto de lo que ellos perciben que reciben por sus impuestos. Sin embargo, las variables que implican la percepción de la gente son difíciles de capturar. Un municipio puede estar mejorando la cobertura en servicios y no ser percibido así o de ese modo por la ciudadanía por distintos factores.

En cuanto a las variables político-electorales, se tienen tres observaciones. Uno, el PAN parece recaudar más, en contra de lo esperado de un partido conservador, más de derecha (que preferiría impuestos indirectos sobre los directos). Pero se pude explicar porque, de acuerdo con su perfil, estas administraciones busquen invertir más y/o sean más renuentes a endeudarse, así como por el perfil del municipio: que el PAN tienda a gobernar más 
en municipios más poblados y ricos. Dos, la competencia electoral aparece como un factor significativo: mientras más grandes los márgenes electorales entre el primero y el segundo lugar, más recaudación; lo que indica que un gobierno, al percibir la amenaza de no ser votado, no quiere ser impopular ${ }^{26}$ cobrando impuestos. Tres, en algunos modelos la convergencia partidista entre el gobernador y el alcalde tiene una relación positiva y significativa, especialmente en el modelo que incluye efectos fijos municipales (modelo 6). Esto parece indicar que cuando un municipio elige un alcalde del mismo partido del gobernador, aumentan las posibilidades de que un gobierno municipal tome las acciones para recaudar más y éstas no sean bloqueadas por el siguiente nivel de gobierno.

Los factores administrativos, entendidos como de capacidad institucional, están evaluados en los modelos 7 a 10. Los resultados aquí muestran que una mayor proporción de empleados del ayuntamiento de base (sindicalizado) o de confianza, parece no afectar la capacidad institucional que se tenga para cobrar predial en las tesorerías. Las variables "actualizar catastro" y "actualizar valores" están medidas de uno a tres, donde el uno significa datos actualizados en el mismo año, el dos en los últimos dos años y el tres en más de dos años. Los resultados de los modelos, como se esperaba, nos dicen que mientras más actualizados estén el padrón catastral y los valores catastrales, mayor será la recaudación predial.

Los modelos 11 y 12 incluyen todas las variables de los tres tipos de determinantes del predial que se plantean en la literatura (económicos, administrativos y de economía política). De nuevo, pobreza, población, participaciones per cápita, cobertura de agua y competencia electoral son significativas con los mismos signos descritos anteriormente. Ambos modelos presentan una $r$ cuadrada de 0.30 , lo que sugiere que los determinantes económicos, políticos y administrativos, según se miden aquí, explican alrededor de $30 \%$ de la variación en la recaudación predial per cápita.

\section{Resultados de los modelos econométricos considerando los municipios con más de 100000 habitantes}

Los rasgos más sobresalientes de los municipios en México son, quizás, su gran heterogeneidad y sus recursos económicos limitados. Los municipios urbanos y rurales, por ejemplo, presentan problemáticas muy distintas. Bajo

${ }^{26}$ Para precisar el término popular según se aprecia en este trabajo, remitirse a la nota al pie núm. 23 . 
esta idea se corrieron algunos modelos considerando sólo a los municipios urbanos de 100000 habitantes y más. El Cuadro 5 nos muestra los resultados de cinco modelos y analiza los factores económicos y políticos que pueden impactar el nivel de recaudación predial. El fin de este ejercicio es saber si el peso de las variables explicativas sigue siendo el mismo y actúan en la misma dirección al considerar sólo los municipios "más poblados". Los municipios con más de 100000 habitantes representan el 56\% de la población del país, pero sólo el 7.4\% de los municipios en 2010.

Lo más notable de los resultados es la consistencia de éstos con los resultados de los modelos que consideran la totalidad de los municipios del país. Los factores económicos, como los niveles de pobreza y analfabetismo, siguen impactando negativamente a la recaudación. Igualmente, las participaciones y los ingresos no tributarios, mismos que se leen como recursos alternos, siguen mostrando signos positivos y significativos. Hay dos grandes diferencias entre los modelos de los municipios de más de 100000 habitantes y de todo el universo. Uno, la población en los primeros parece ya no importar. Dos, dentro de los factores políticos se encuentra que la convergencia partidista entre el alcalde y el gobernador ahora aparece como una variable correlacionada negativamente en dos de los modelos. Esto se puede interpretar como que para los municipios más poblados es más posible enfrentar al gobierno del estado en caso de que éste se quiera interponer a las propuestas municipales para recaudar más.

\section{Conclusiones}

Este trabajo ha ofrecido evidencia empírica para valorar el poder explicativo de algunas de las variables que la literatura considera como determinantes del nivel de recaudación. Un hallazgo central del análisis multivariado es que los factores políticos son relevantes para el desempeño de la recaudación, tanto en términos del partido que gobierna (los municipios en manos del PAN han recaudado más que los gobernados por el PRI o el PRD) como de la competencia electoral y las relaciones entre los gobiernos municipales y estatales. Los municipios que enfrentan mayor competencia electoral no toman las acciones necesarias para recaudar más predial, ${ }^{27}$

${ }^{27}$ Las acciones para aumentar la recaudación predial podrían ser varias: $i$ ) aumentar las tasas del impuesto; ii) aumentar los valores catastrales, sea por cambios en el uso del suelo o por simple acercamiento de los valores catastrales a los de mercado; iii) reducir las exenciones, tasas preferenciales o descuentos de los cuales gozan los contribuyentes del predial en los municipios; iv) aumentar la eficiencia para cobrar el impuesto mediante mejores procesos de 
pues sopesan que ello tendrá un costo político. Esto indica que los políticos a nivel local adoptan posturas populistas para apelar al electorado; es decir, los tomadores de decisiones del ámbito local, en un contexto competitivo electoralmente, buscan agradar a los votantes aplazando las innumerables medidas que se pueden tomar para aumentar el predial. Prefieren evitar los conflictos que naturalmente resultarían de acciones que busquen aumentar la recaudación.

En este trabajo se planteó que, además de los factores políticos de corte electoral, existían otros también de corte político que podrían influir en el nivel de recaudación predial. Se propuso que el desempeño de los gobiernos municipales en cuanto a su eficacia en el gasto (medido a través de indicadores de cobertura de servicios básicos) podría determinar el nivel de recaudación, ya que un mejor desempeño tendría un efecto positivo en las tasas de cumplimiento. Estos factores presentaron resultados mixtos. De las variables que miden cobertura de servicios básicos, sólo el agua tuvo el comportamiento esperado: mientras mayor cobertura de agua, más recaudación.

El análisis estadístico sugiere que los factores de capacidad administrativa o institucional son relevantes para explicar el nivel de recaudación. Según fue posible medir la capacidad institucional de los gobiernos municipales, con base en las fuentes existentes, se concluye que el efecto más importante y correlacionado positivamente con la recaudación es el tener registros y valores catastrales actualizados. Sin embargo, como ya habíamos mencionado, se reconoce que la medición de esta variable (capacidad institucional del gobierno municipal para cobrar predial) para estudios estadísticos longitudinales que abarcan la totalidad de municipios del país plantea un reto que es más preciso desarrollar a través de estudios de caso que permitan el diseño de instrumentos de medición de capacidad institucional para cada municipio, como hace Unda (2018).

El análisis estadístico nos permite establecer también que las variables económicas determinan límites a la recaudación. Los municipios más poblados y más desarrollados económicamente, con la desigualdad que esto conlleva, recaudan más. En cambio, las variables que reflejan los recursos alternos a los que los municipios tienen acceso no parecen afectar negativamente al nivel de recaudación. En concreto, las transferencias que reciben los municipios (aportaciones y participaciones) no están desincentivando el esfuerzo tributario predial. Este hallazgo contraviene lo sugerido en la literatura anteriormente. A partir de este resultado, uno podría suponer que

cobro, control y sanción (lo que implica el aumento de la capacidad institucional de la administración municipal), etcétera. 


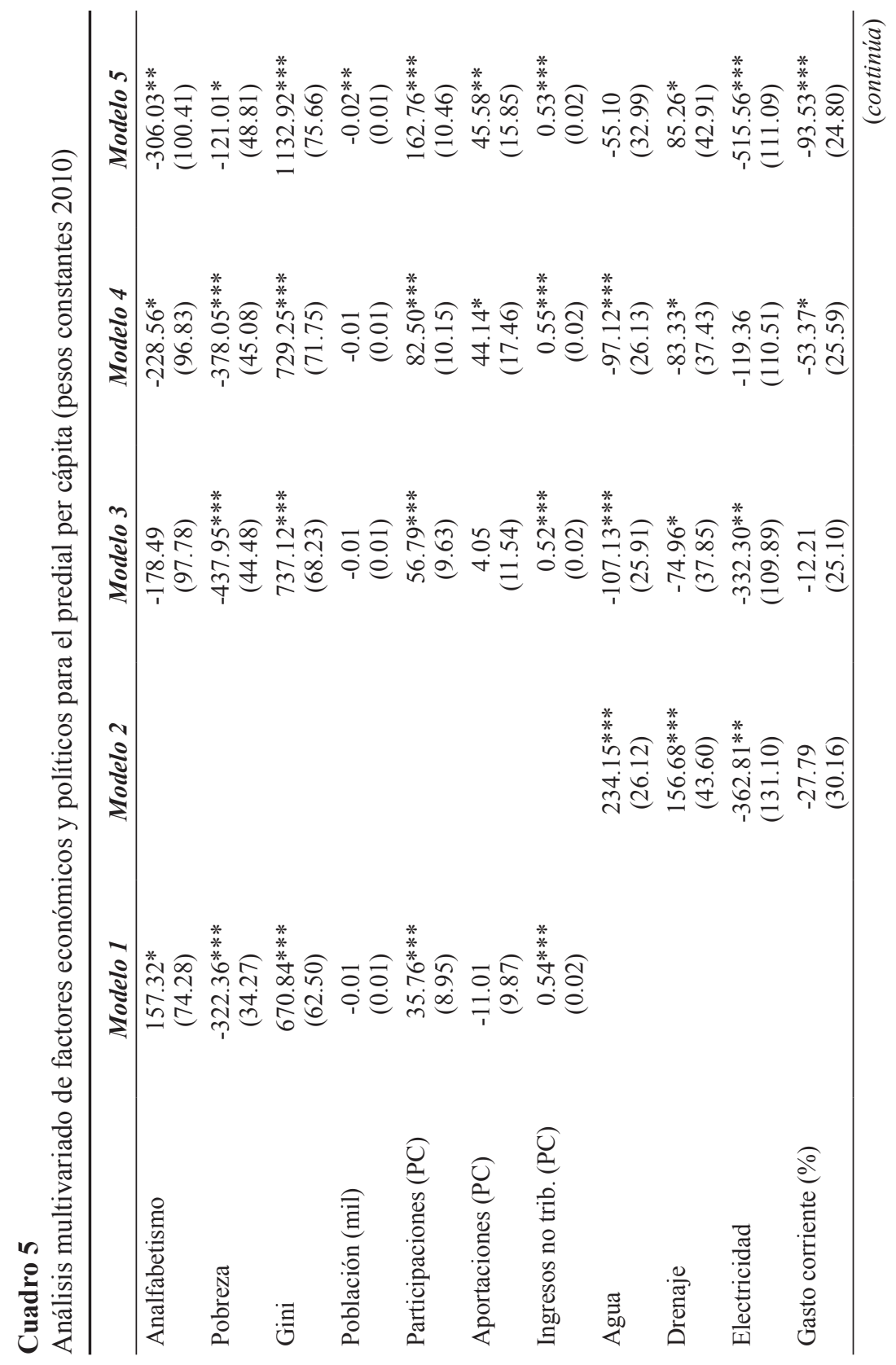




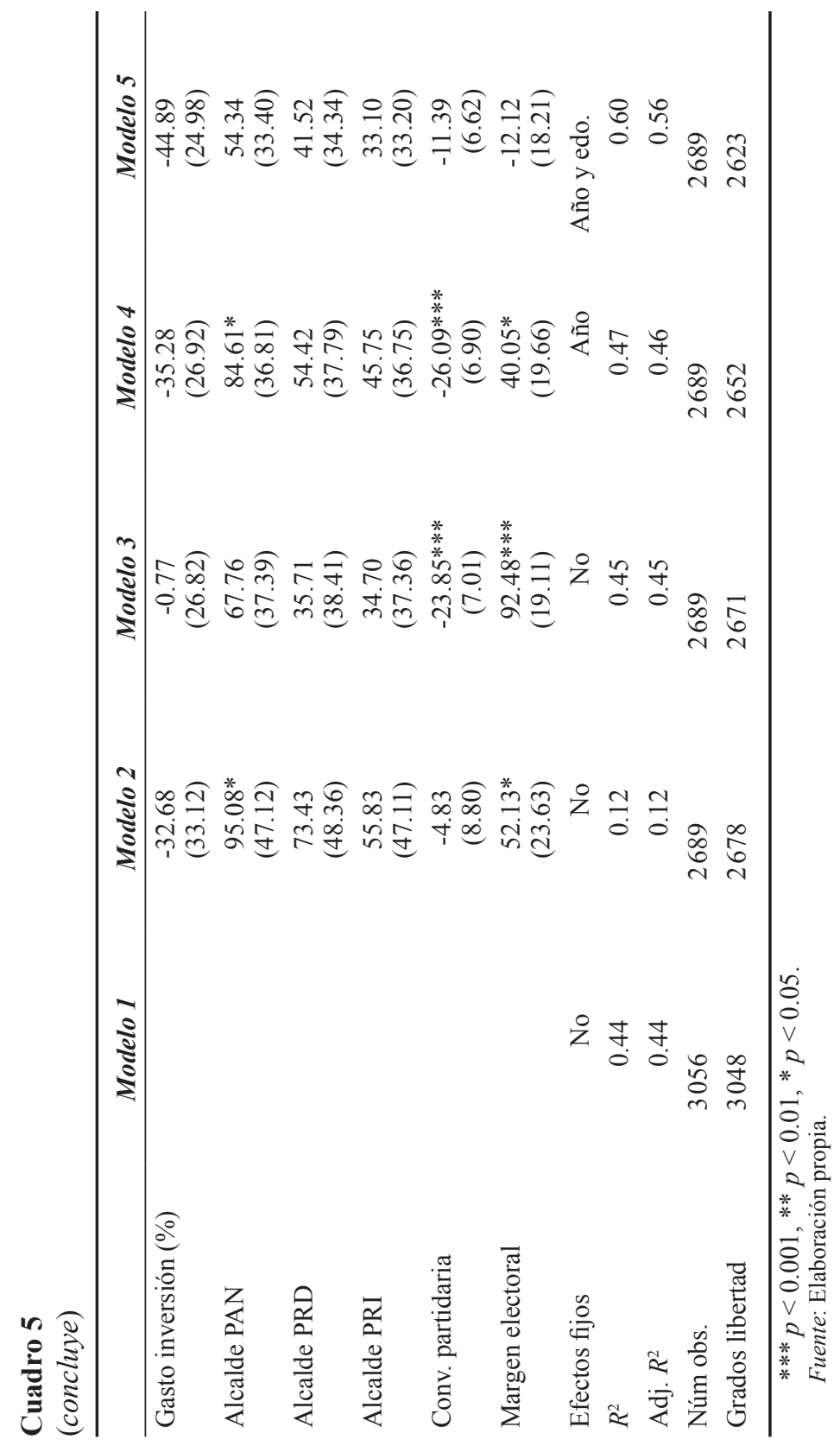


los cambios que se han implementado en las fórmulas y criterios de distribución de las aportaciones y las participaciones han ayudado a corregir los incentivos negativos que imponían a la recaudación. Aunque cabe preguntarse qué tanto los criterios y fórmulas de distribución actúan negativamente en la recaudación municipal cuando los encargados de las finanzas del municipio desconocen cómo se determina el monto de las transferencias que reciben, lo cual es una realidad en la mayoría de los municipios del país.

Desde principios de los años ochenta, cuando los esfuerzos de descentralización fiscal se pusieron en marcha, la recaudación predial municipal aumentó ligeramente en el país. En la actualidad, los municipios mexicanos recaudan casi tres veces más de que lo que recaudaban en predial en 1990 (Gráfica 4). Se puede apreciar que este aumento es más rápido a partir del año 2000, pero a pesar de ello la recaudación sigue estando muy lejos de su potencial. Como se ha sugerido en este trabajo, los factores que han contribuido a este comportamiento en la recaudación son variados. Los grandes catalizadores han sido, quizás, los procesos de descentralización y democratización que han vivido los gobiernos municipales. Si bien esto ha redundado en gobiernos municipales con más capacidad institucional, en algunos casos también ha significado mayor competencia política, la cual parece no ser del todo positiva para el aumento de la recaudación. Este fenómeno define uno de los retos más grandes de las finanzas municipales: aumentar la recaudación predial asumiendo el costo político que conlleva en un entorno de alta competencia electoral.

\section{Bibliografía}

Bahl, R. y Martínez-Vazquez, J. (2007). The property tax in developing countries: Current practice and prospects. (Documento de Trabajo, núm. 07RB1). Lincoln Institute of Land Policy. Recuperado de https:// www.lincolninst.edu/sites/default/files/pubfiles/1256_Bahl\%20Final. pdf

Banobras. (1997). La modernización catastral en el Programa de 100 Ciudades. Federalismo y Desarrollo, 58.

Bird, R. y Casanegra, M. (ed.). (1992). Improving tax administration in developing countries. Washington, DC: International Monetary Fund.

Burgess, R. y Stern, N. (1993). Taxation and development. Journal of Economic Literature, 31(2), 762-830. Recuperado de http://personal.lse. ac.uk/sternn/074NHS.pdf 
Bustamante, N. (2001). Impuesto predial en Hermosillo. Estudios Demográficos y Urbanos, 16(2), 415-439. Recuperado de https://estudios demograficosyurbanos.colmex.mx/index.php/edu/article/view/1124/ 1117

Canavire, G. y Zúñiga, N. (2010). Fiscal transfers a curse or blessing? Evidence of their effect on tax effort for municipalities in Sinaloa, Mexico. (Documento de Trabajo, núm. 10-30). Atlanta, GA: Georgia State University. Recuperado de https://icepp.gsu.edu/files/2015/03/ispwp1030. pdf

Carrera, A. P. y Rivera, G. (2012). Diagnóstico institucional de la gestión hacendaria de los municipios del Estado de México. Toluca, Estado de México: Consejo Editorial de la Administración Pública Estatal.

Cruz Vásquez, M. (2011). Causas de la baja recaudación del impuesto predial en el estado de Oaxaca. El efecto de los usos y costumbres. Ponencia presentada en XVI Congreso Internacional de Contaduría, Administración e Informática. México D.F., 5 a 7 de octubre.

Daud, D., Alias, B. y Muthuveerappan, C. (2008). The needs for capacity building in local government in Malaysia. Ponencia presentada en International Real Estate Research Symposium 2008 "Benchmarking, Innovation and Sustaining Real Estate Market Dynamics", Kuala Lumpur, Malasia, 30 de abril.

Di John, J. (2006). The political economy of taxation and tax reform in developing countries. (Documento de Trabajo, núm. 2006/74.UNU-WIDE). Recuperado de https://www.wider.unu.edu/sites/default/files/rp200674.pdf

Fernández Ruiz, J., Valencia Carmona, S. y Pérez López, M. (2001). La reforma constitucional de diciembre de 1999 al artículo 115. Cuestiones Constitucionales. Revista Mexicana de Derecho Constitucional, 1(4). Recuperado de http://dx.doi.org/10.22201/iij.24484881e.2001.4.5616

Hinrichs, H. H. (1966). A general theory of tax structure change during economic development. Cambridge, MA: The Law School of Harvard University.

Ibarra, J. y Sotres, L. (2009). Determinantes de la recaudación del impuesto predial en Tamaulipas: instituciones y zona frontera norte. Frontera Norte, 21(42), 165-192. Recuperado de http://www.redalyc.org/articulo. oa? id $=13612040007$

Ibarra, J. y Sotres, L. (2013). Las instituciones fiscales como paliativo para enfrentar crisis financieras: el impuesto predial en el estado de Coahuila. En J. E. Mendoza Cota (coord.), La crisis financiera internacional. 
Efectos sectoriales en México y en su frontera (pp. 315-354). Tijuana, BC: El Colegio de la Frontera Norte.

Ibarra, J. y Sotres, L. (2014). Diferencias en la recaudación del impuesto predial en la zona fronteriza: evidencia en los municipios de Chihuahua. Estudios Demográficos y Urbanos, 29(1), 53-87. Recuperado de https: //estudiosdemograficosyurbanos.colmex.mx/index.php/edu/article/ view/1455

Ibarra, J., González, H. y Sotres, L. (2013). Aspectos políticos de la dependencia financiera en los municipios mexicanos. Revista Mexicana de Ciencias Políticas y Sociales, 58(217), 139-170. Recuperado de http://www.scielo.org.mx/scielo.php?script=sci_arttext\& pid $=$ S0185-19182013000100008

Indesol y Sedesol. (2000). Encuesta Nacional sobre Desarrollo Institucional Municipal. México: Instituto Nacional de Desarrollo Social / Secretaría de Desarrollo Social. Recuperado de http://bdsocial.inmujeres. gob.mx/index.php/endesmun-130

INEGI. (1990). Finanzas públicas estatales y municipales. Aguascalientes, Ags., México: Instituto Nacional de Estadística y Geografía. Recuperado de https://www.inegi.org.mx/temas/finanzas/

INEGI. (2009). Encuesta Nacional de Gobierno, Seguridad Pública y Justicia. Aguascalientes, Ags., México: Instituto Nacional de Estadística y Geografía. Recuperado de https://www.inegi.org.mx/app/biblioteca/ ficha.html?upc $=702825001964$

INEGI. (2011a). Encuesta Nacional de Calidad e Impacto Gubernamental. Aguascalientes, Ags., México: Instituto Nacional de Estadística y Geografía. Recuperado de https://www.inegi.org.mx/programas/ encig/2011/

INEGI. (2011b). Censo Nacional de Gobiernos Municipales y Delegacionales. Aguascalientes, Ags., México: Instituto Nacional de Estadística y Geografía.Recuperadodehttps://www.inegi.org.mx/programas/cngmd/ 2011/default.html

INEGI. (2013). Censo Nacional de Gobiernos Municipales y Delegacionales. Aguascalientes, Ags., México: Instituto Nacional de Estadística y Geografía. Recuperado de https://www.inegi.org.mx/programas/ cngmd/2013/default.html

Kirchgässner, G. (2001). The effects of fiscal institutions on public finance: A survey of the empirical evidence. En S. L. Winer y H. Shibata (eds.), Political economy and public finance: The role of political economy in the theory and practice of public economics (pp. 145-177). Cheltenham, Reino Unido: Edward Elgar. 
Levi, M. (1989). Of rule and revenue. Berkeley / Los Angeles, CA: University of California Press.

Lotz, J. R. y Morss, E. R. (1970). A theory of tax level determinants for developing countries. Economic Development and Cultural Change, 18(3), 328-341. Recuperado de https://www.jstor.org/stable/1152062?s eq=1\#metadata_info_tab_contents

Meene, S. y Brown, R. (2007). Towards an institutional capacity assessment framework for sustainable urban water management. $11^{\text {th }}$ Int. Rainwater Catchment Systems Conf. and $5^{\text {th }}$ Int. Water Sensitive Urban Design Conf. Sydney, Australia, 21 a 23 de agosto.

Merino, M. (2004). Los gobiernos municipales de México: el problema del diseño institucional. (Documento de Trabajo, núm. 145). Ciudad de México: Centro de Investigación y Docencia Económica. Recuperado de http://aleph.academica.mx/jspui/handle/56789/3481

Mizrahi, Y. (2004). Capacity enhancement indicators: Review of the literature. Washington, DC: World Bank Institute.

Moreno, C. (2007). Gasto público y elecciones: una explicación política de la asignación de los presupuestos municipales en México. Foro Internacional, 188(2), 408-434. Recuperado de https://forointernacional. colmex.mx/index.php/fi/article/view/1846/1836

Musgrave, R. (1969). Fiscal systems. New Haven, CT: Yale University Press. OCDE. (2012). Mejores prácticas registrales y catastrales en México. Organización para la Cooperación y el Desarrollo Económicos.

OCDE. (2014). Revenue statistics database. Organización para la Cooperación y el Desarrollo Económicos. Recuperado de https://stats.oecd.org/ Index.aspx? DataSetCode $=\mathrm{REV}$

Ordoño, A., Azpeitia, F. y González, A. (1997). Características y evolución del impuesto predial en México. Federalismo y Desarrollo, 58, 39-51.

Peña Ahumada, J. A. y Wence, L. A. (2011). La distribución de transferencias federales para municipios. ¿Qué incentivos se desprenden para el fortalecimiento de sus haciendas públicas? Hacienda Municipal. 115, 79-96. Recuperado de http://www.inafed.gob.mx/work/dso/la distribucion_de transferencias_federales_para_municipios.pdf

Pérez López, M. y Núñez Mercado, J. (2001). La nueva estructura del derecho municipal mexicano. Notas sobre la reforma constitucional en materia municipal 1999. Cuestiones Constitucionales, 4, 254-267.

Poterba, J. y Von Hagen, J. (1999). Fiscal institutions and fiscal performance. Chicago, IL: Chicago University Press / NBER.

Raich, U. (2004). Impacto de la descentralización del gasto en los municipios en México. En J. P. Guerrero (coord.), Impuestos y gasto públi- 
co en México, desde una perspectiva multidisciplinaria (pp. 395-446). Ciudad de México: Miguel Ángel Porrúa.

Ramírez, A. (2003). Evidencia empírica acerca de los determinantes políticos e institucionales del endeudamiento municipal en México. Gaceta de Economía, 9(17), 119-139.

Ruelas Ávila, I. (2012). Análisis del impuesto predial en México. (Tesis de maestría, Universidad de Chile, Santiago de Chile). Recuperado de http://repositorio.uchile.cl/handle/2250/107892

Santana, S. (2000). Acciones necesarias para la implementación de la reciente reforma al artículo 115 constitucional: aspectos hacendarios. Hacienda Municipal, 72, 15-22.

Santana, S. y Sedas, C. (1999). El artículo 115 constitucional y sus reformas: comentarios a los aspectos hacendarios de la reforma de 1999. Hacienda Pública Municipal, 19(68), 21-35.

Sedesol. (2002). Encuesta Nacional a Presidentes Municipales sobre Desarrollo Social. Ciudad de México: Secretaría de Desarrollo Social. Recuperado de http://bdsocial.inmujeres.gob.mx/index.php/enapren-128/ encuesta-nacional-a-presidentes-municipales-sobre-desarrollo-social

Sedesol. (2004). Encuesta Nacional de Gobiernos Municipales. Ciudad de México: Secretaría de Desarrollo Social. Recuperado de http:// bdsocial.inmujeres.gob.mx/index.php/engm-134/encuesta-nacional-de-gobiernos-municipales

Silva-Herzog, J. (1982). Diario de debates de la Cámara de Diputados. Legislatura LII, 1(49), 11 de diciembre. Recuperado de http://cronica. diputados.gob.mx/DDebates/52/1er/Ord/19821211.html

Sour, L. (2004). El sistema de transferencias federales en México: ¿premio o castigo para el esfuerzo fiscal de los gobiernos locales urbanos? Gestión y Política Pública, 13(3) 733-751. Recuperado de http://www. gestionypoliticapublica.cide.edu/num_anteriores/Vol.XIII_NoIII_2do sem/LauraSour.pdf

Sour, L. (2008). Un repaso de los conceptos sobre capacidad y esfuerzo fiscal, y su aplicación en los gobiernos locales mexicanos. Estudios Demográficos y Urbanos, 23(2), 271-297. Recuperado de https:// estudiosdemograficosyurbanos.colmex.mx/index.php/edu/article/ view/1312

Tanzi, V. (2000). Taxation in Latin America in the last decade. (Documento de Trabajo, núm. 76). Stanford: Center for Research on Economic Development and Policy Reform. Recuperado de http://www-siepr. stanford.edu/conferences/FFReform_LA/Tanzi_Taxation_in_LAC.pdf 
Tilly, C. (1992). Coercion, capital and European states: AD 990-1992. Oxford: Wiley- Blackwell.

Unda, M. (2018). Los límites de la recaudación predial en los municipios urbanos de México: un estudio de casos. Estudios Demográficos y Urbanos, 33(3), 601-637. Recuperado de https://estudiosdemograficos yurbanos.colmex.mx/index.php/edu/article/view/1741/pdf

Unda, M. y Moreno, C. (2015). La recaudación del impuesto predial en México: un análisis de sus determinantes económicos en el período 19692010. Revista Mexicana de Ciencias Políticas y Sociales, 60(225), 45-78. Recuperado de http://www.revistas.unam.mx/index.php/rmcpys/ article/view/51788/46942

World Bank. (2009). Reshaping economic geography (World Development Report). Washington, D.C.: The World Bank. Recuperado de http://documents.worldbank.org/curated/en/730971468139804495/ pdf/437380REVISED01BLIC1097808213760720.pdf

World Bank and United Cities and Local Government. (2008). Decentralization and local democracy in the world: First global report by united cities and local government. Washington, DC: World Bank.

Zúñiga Espinoza, N. G. (2010). Transferencias condicionadas e impuesto predial para los municipios de Sinaloa, México. Dimensión Económica, 1(3), 16-28. Recuperado de http://www.journals.unam.mx/index. $\mathrm{php} / \mathrm{rde} /$ article/view/21548

\section{Acerca de la autora}

Mónica Unda Gutiérrez es profesora investigadora en Marquette University (Wisconsin, Estados Unidos). Anteriormente fue profesora investigadora en el Instituto Tecnológico y de Estudios Superiores de Occidente (ITESO) y en El Colegio de México, A.C. Obtuvo el doctorado y la maestría en Estudios para el Desarrollo por la Universidad de Londres. Es miembro del Sistema Nacional de Investigadores. Su investigación se centra en las finanzas municipales y la economía política de los impuestos en México. Sus artículos sobre reformas tributarias en México y finanzas municipales han sido publicados por revistas indexadas como: Economic History Research, Estudios Demográficos y Urbanos y Revista Mexicana de Ciencias Políticas y Sociales. ORCID: https://orcid.org/0000-0001-6231-1208

Entre sus publicaciones destaca el libro:

Aboites, L. y Unda, M. (2011). El fracaso de la reforma fiscal de 1961. Artículos publicados y documentos del archivo de Victor L. Urquidi en 
torno a la cuestión tributaria en México (selección y ensayo introductorio). Ciudad de México: El Colegio de México, A.C. Recuperado de https://www.jstor.org/stable/j.ctv512s7v

Recepción: 22 de junio de 2018. Aceptación: 23 de mayo de 2019. 